\title{
An Active Motor Model for Adaptation by Vertebrate Hair Cells
}

\author{
John A. Assad ${ }^{1 . a}$ and David P. Corey ${ }^{2,3}$ \\ 'Department of Neurobiology and PProgram in Neuroscience, Harvard Medical School, and ${ }^{3 H o w a r d ~ H u g h e s ~ M e d i c a l ~}$ \\ Institute and Department of Neurology, Massachusetts General Hospital, Boston, Massachusetts 02114
}

\begin{abstract}
Bullfrog saccular hair cells adapt to maintained displacements of their stereociliary bundles by shifting their sensitive range, suggesting an adjustment in the tension felt by the transduction channels. It has been suggested that steadystate tension is regulated by the balance of two calciumsensitive processes: passive "slipping" and active "tensioning." Here we propose a mathematical model for an adaptation motor that regulates tension, and describe some quantitative tests of the model. Slipping and tensioning rates were determined at membrane potentials of $-\mathbf{8 0}$ and +80 $\mathrm{mV}$. With these, the model predicts that the $\mu(X)$ curve (relating bundle displacement and channel open probability) should shift negatively by $124 \mathrm{~nm}$ when the cell is depolarized, with an exponential time course that is slower on depolarization from -80 to $+80 \mathrm{mV}$ than on repolarization. This was observed: on depolarization, the $I(X)$ curve shifted by an average of $139 \mathrm{~nm}$, and displayed the expected difference in rates at the two potentials. Because the negative shift of the $l(X)$ curve on depolarization represents an increase in the tension on transduction channels, the model also predicts this tension should cause an unrestrained bundle to pivot negatively by $99 \mathrm{~nm}$ on depolarization. Such movement was observed using high-resolution video microscopy; its amplitude was variable but ranged up to about $100 \mathrm{~nm}$, and its time course was asymmetric in the same way as that of the $I(X)$ curve shift. In additional comparisons, the active bundle movements and $f(X)$ curve shift exhibited a similar steady-state voltage dependence, and were both reversibly abolished by reduced bath $\mathrm{Ca}^{2+}$ or by the transduction channel blocker streptomycin. Lastly, among different cells, the amplitude of the movement increased with the size of the transduction current. Thus, a quantitative mechanical model for adaptation also accounts for the observed mechanical behavior of the bundle, suggesting that the same mechanism is responsible for both, and that adaptation is mediated by an active, force-producing mechanism.
\end{abstract}

\footnotetext{
Received Oct. 7, 1991; revised Mar. 18, 1992; accepted Mar. 27, 1992.

This work was supported by the Howard Hughes Medical Institute, NIH Grant DC00304, Office of Naval Research Grants N00014-88-K-0078 and N00014-91J-I 159, and an NSF predoctoral fellowship to J.A.A. We are grateful to Gordon M. G. Shepherd, Stephen Cannon, Steven Block, Jonathon Howard, Bruce Bean, Campbell Searle, and Winfried Denk for comments.

Correspondence should be addressed to David P. Corey, Wellman 414, Massachusetts General Hospital, Boston, MA 02114.

a Present address: Department of Physiology and Center for Visual Science, University of Rochester, Rochester, NY 14642.

Copyright $\subseteq 1992$ Society for Neuroscience 0270-6474/92/123291-19\$05.00/0
}

The proximal stimulus by which all vertebrate auditory and vestibular organs gain their mechanical sensitivity is the deflection of stereociliary bundles of hair cells. Bundle deflection is posited to stretch elastic linkages ("gating springs") that attach to the transduction channels; the resulting tension pulls the channels open (Corey and Hudspeth, 1983b; Howard and Hudspeth, 1988). Fine, filamentous linkages are visible in electron micrographs extending from the tip of each stereocilium to the side of the next adjacent, taller stereocilium. These "tip links" are apparently the structural correlates of the biophysically defined gating springs (Pickles et al., 1984; Assad et al., 1991). The gating mechanism is remarkably sensitive: hair cells show threshold activity with bundle displacements of a few nanometers, and the entire sensitive range is a few hundred nanometers (Hudspeth, 1989). However, such acute sensitivity would apparently restrict the dynamic range of the cells. For example, the response of the vibration-sensitive bullfrog sacculus reaches a maximum with body accelerations of only $1 \mathrm{~mm} / \mathrm{sec}^{2}$ (Koyama et al., 1982). The tonic acceleration due to gravity $(10,000 \mathrm{~mm} /$ $\mathrm{sec}^{2}$ ) would seem to saturate the organ, rendering it useless for vibration detection. Accordingly, saccular hair cells have evolved an adaptation mechanism that continually shifts the sensitive range of the cells to cancel the effects of static stimuli (Eatock et al., 1979, 1987; Corey and Hudspeth, 1983a). Within tens of milliseconds following a maintained positive or negative displacement, the sigmoidal relationship between receptor current and bundle displacement [the $I(X)$ curve] shifts along the $\mathrm{X}$-axis toward the new displacement, and channels return toward their normal "resting" open probability of about $20 \%$. Thus, saccular hair cells maintain both high sensitivity and a broad dynamic range.

Several experiments have suggested that hair cell adaptation involves a mechanical adjustment of the tension stimulus reaching the transduction channels. Using a flexible glass probe to displace the bundle in the positive direction, Howard and Hudspeth (1987) were able to measure a decrease in bundle stiffness that developed with the same time course as the adaptive decline of receptor current. They suggested that the gating springs could gradually relax under the tension produced by bundle displacement, perhaps by slipping of their insertions. As the springs slacken, the set point of the transduction process would shift relative to the absolute position of the bundle-equivalent to a translation of the $I(X)$ curve along the displacement axis. Asymmetry in the channel gating kinetics had previously led to the suggestion that the gating spring was like a string-capable of exerting force in tension but not in compression (Corey and Hudspeth, 1983b). Thus, it was supposed additionally that the gating spring attachment was associated with a force generator that could tighten to restore or maintain a resting tension. 
The initial rate of adaptation increases linearly with the size of the stimulus for positive displacements, even for displacements that saturate the response-suggesting that the adaptation process precedes transduction (Hacohen et al., 1989). In contrast, the rate is nearly independent of step amplitude for large negative displacements that would cause the gating spring to be slack, and we suggested that this rate represents the intrinsic (no-load) rate of the active element. In this vicw, the equilibrium open probability of the transduction channels is determined by the balance of these two processes-passive "slipping," which relaxes the tension on the channels, and active "tensioning" (Hudspeth, 1985; Howard and Hudspeth, 1987; Assad et al., 1989; Hacohen et al., 1989).

The rate of adaptation to positive displacements (slipping) is reduced by lowering extracellular calcium ion concentration (Eatock et al., 1979, 1987; Hacohen et al., 1989) or by including high concentrations of the $\mathrm{Ca}^{2+}$ chelator BAPTA in the intracellular solution (Crawford et al., 1989). It is also reduced by depolarizing the hair cell (Assad et al., 1989; Crawford et al., 1989), but the voltage dependence is eliminated if the bath $\mathrm{Ca}^{2+}$ is reduced (Assad et al., 1989). These all suggest that $\mathrm{Ca}^{2+}$ entry into the stereocilia potentiates the slipping process. However, the rate of adaptation to negative displacements (tensioning) is less sensitive to bath $\mathrm{Ca}^{2+}$ (Hacohen ct al., 1989). Either reduced bath $\mathrm{Ca}^{2+}$ or depolarization increases the resting open probability of the transduction channels (Corey and Hudspeth, 1983b; Assad et al., 1989; Hacohen et al., 1989), consistent with the hypothesis that the steady-state tension is controlled by the interplay of slipping and tensioning.

Other interpretations exist: Crawford et al. (1989) observed the voltage-dependent decline in receptor current and shift of the $I(X)$ curve characteristic of adaptation, and they observed a decrease in bundle stiffness that developed during maintained bundle displacements. However, the stiffness change was voltage independent, suggesting that the decline in stiffness was unrelated to adaptation. Accordingly, they proposed that adaptation was a $\mathrm{Ca}^{2+}$-dependent change in open probability intrinsic to the transduction channels rather than a mechanical adjustment of the tension applied to the channels (Crawford et al., 1989, 1991).

In this article, we develop and test a quantitative description of adaptation, which includes a "motor" element capable of generating mechanical tension in the gating springs. With parameters derived from a measurement of initial rates, it predicts the amplitude and time course of the $I(X)$ position following voltage changes. It also predicts an active, voltage-dependent movement of an unconstrained bundle, which was observed (Assad et al., 1989).

\section{Materials and Methods}

Preparation. Saccular hair cells were isolated from adult bullfrogs following a procedure modified from Assad et al. (1989). All steps of the dissociation were done at room temperature in a standard solution containing (in mM) $120 \mathrm{NaCl}, 2 \mathrm{KCl}, 0.1 \mathrm{CaCl}_{2}, 3$ dextrose, and $5 \mathrm{HEPES}$ at $\mathrm{pH} 7.25$; for some steps divalent ion concentrations were altered as described. The saccular cavity was exposed, and the standard solution, containing in addition $1 \mathrm{~mm}$ EDTA to bring free $\mathrm{Ca}^{2+}$ to $10^{-8} \mathrm{M}$, was dripped into the perilymphatic space for $15 \mathrm{~min}$. Low-Ca ${ }^{2+}$ solutions abolish the transduction process (Sand, 1975; Corey and Hudspeth, 1979; Assad et al., 1991; Crawford et al., 1991); however, the tight junctions of the saccular epithelium presumably provided a diffusion barrier that prevented the EDTA from contacting the hair bundles. The $\mathrm{CaCO}_{3}$-based otolithic mass may have also buffered $\mathrm{Ca}^{2+}$ levels around the bundles even if the chelator penetrated the endolymphatic space.
The sacculi were dissected out and incubated for $30 \mathrm{~min}$ in standard solution containing $75 \mu \mathrm{g} / \mathrm{ml}$ bacterial protease type XXIV (Sigma) to loosen the otolithic membranes. They were then treated for $10 \mathrm{~min}$ with $0.04 \mathrm{mg} / \mathrm{ml}$ DNase I (Worthington) in standard solution with $1 \mathrm{~mm}$ $\mathrm{CaCl}_{2}$ and $0.4 \mathrm{~mm} \mathrm{MgCl}$, to reduce clumping of the cells. Sacculi were finally transferred to the recording chamber, which was filled with the same DNase solution. After the otolithic membrane had been peeled away, the hair cells were flicked from the macula using an eyelash and allowed to settle. The recording chamber's glass coverslip bottom was cleaned before each experiment with a saturated solution of $\mathrm{KOH}$ in ethanol.

Electrical recording. Membrane currents were recorded using wholecell patch-clamp techniques as previously described (Assad et al., 1989). Borosilicate glass electrodes (4-6 M $)$ ) were sealed to the basolateral membranes of the cells; residual series resistance after compensation was typically 5-7 M 2 . Because total membrane current was less than $500 \mathrm{pA}$, steady-state voltage errors arising from residual series resistance were estimated to be less than $4 \mathrm{mV}$. Signals were filtered at $5 \mathrm{kH} /$ and digitized on line with a PDP-11/73 computer system. Pipettes were filled with (in mM) $85 \mathrm{CsCl}, 2 \mathrm{MgCl}_{2}, 10 \mathrm{EGTA}, 2 \mathrm{Na}_{2} \mathrm{ATP}$, and 5 HEPES. The bath contained (in $\mathrm{mM}$ ) $120 \mathrm{NaCl}, 2 \mathrm{KCl}, 4 \mathrm{CaCl}_{2}, 5 \mathrm{CsCl}$, 3 dextrose, and 5 HEPES. $\mathrm{Cs}^{+}$was present to block inwardly rectifying potassium channels (Barres et al., 1990). This typically increased input resistance of the cells to well over $1 \mathrm{G} \Omega$ at a holding potential of -80 $\mathrm{mV}$. The substantial hypo-osmolarity of the internal solution relative to the bath was found to improve the mechanical stability of the cells and prolong the duration of recording. Liquid junction potentials at the tip of the electrode were electronically nulled before making a seal on the cell. The measured junction potential for the solutions used in our experiments was $-5 \mathrm{mV}$; records shown in the Results were not corrected for this offset.

Mechanical stimulation. Transduction currents were elicited by displacing the stereociliary bundle with a hollow glass probe affixed to the kinocilium. The probe was moved by a piezoelectric bimorph manipulator of the "pi" configuration, which allowed displacements in any direction in the horizontal plane (Corey and Hudspeth, 1980). In most experiments the probe was sealed to the kinociliary bulb by mouth suction applied to the back of the stimulus probe via a thin strand of polyethylene tubing (Holton and Hudspeth, 1986). The reliable mechanical coupling obtained with suction was essential for the complicated displacement protocols and large range of negative and positive displacements.

Iontophoresis. For iontophoresis of aminoglycosides, microelectrodes (resistance, 150-300 M ) were filled with $500 \mathrm{~mm}$ dihydrostreptomycin sulfate (Sigma) and positioned within $5 \mu \mathrm{m}$ of the bundle. A holding current of $300 \mathrm{pA}$ counteracted diffusion of the drug out of the pipette. Ejection currents were 2-10 nA. The effective concentration of drug at the bundle was unknown; however, the concentration was sufficient to block the transduction current completely.

Changing $\mathrm{Ca}^{2+}$. Two different methods were used to lower the concentration of $\mathrm{Ca}^{2+}$ bathing the cells. In experiments in which the bundle was constrained by an attached stimulus probe, a normal bath solution with $\mathrm{Ca}^{2+}$ lowered to $0.1 \mathrm{~mm}$ was delivered by solenoid-controlled ejection from a pipette positioned $\sim 30 \mu \mathrm{m}$ from the cell (ejection pressure $\sim 10 \mathrm{kPa}$ ). When this stream was delivered to an unconstrained bundle, the bundle was deflected by several hundred nanometers. For experiments to record active bundle motion, therefore, a diffusion technique was developed to lower $\mathrm{Ca}^{2+}$. Large-tipped pipettes $(\sim 20 \mu \mathrm{m}$ diameter $)$ were fire polished down to $2-5 \mu \mathrm{m}$ so that they opened into a reservoir several microns from the tip. The pipettes were completely filled with a saline solution containing (in mM) 20 BAPTA $(1,2$-bis $[O$-aminophenoxy] thane- $N, N, N^{\prime}, N^{\prime}$-tetraacetic acid), $96 \mathrm{NaCl}, 2 \mathrm{KCl}, 5 \mathrm{CsCl}, 3$ dextrose, and 5 HEPES, and their back ends were sealed with dental sticky wax to prevent capillary flow in the pipette. During a recording, the pipette was rapidly moved next to the bundle (within $5 \mu \mathrm{m}$ ) so that BAPTA could diffuse out and chelate $\mathrm{Ca}^{2+}$ in its immediate vicinity. The method was not quantitatively reproducible since the spatial spread of the BAPTA decreased continuously as the pipette contents exchanged with the bath; nonetheless, it avoided large mechanical artifacts.

Video recording and analysis. Hair cells were observed with a Zeiss IM-35 inverted microscope equipped with differential interference contrast (DIC) optics, a $63 \times$ Neofluor objective, and a 0.63 NA condenser lens. Optical distortion was reduced by placing a sliver of coverslip over the experimental chamber to flatten the bath meniscus. The image of the bundle was projected onto the faceplate of a Hamamatsu Newvicon camera. The raw video signal was observed on an oscilloscope's TV 
field line display; analog gain and offset were adjusted so that the signal corresponding to the hair bundle just filled the dynamic range of the camera's output. To correlate electrophysiological and video records, a two-channel digital circuit was designed to produce a "bar graph" indicator at the bottom of each video image; bars represented the voltage command and iontophoresis signal during that video field. All video data were recorded onto videotape and later transferred to optical memory disk for frame-by-frame analysis of active bundle motion.

To detect bundle movement, video frames acquired at different voltages were subtracted, and the contrast increased about twofold (Image1, Universal Imaging Corp.). Small changes in position were revealed by light and dark fringes around an object.

To quantify movement, an automated program was used to measure the intensity of selected lines of pixels perpendicular to the stereocilia. Usually two five-pixel-thick lines were selected, one at the tip of the bundle and a second running across the base of the bundle (Fig. 1A). The resulting intensity profiles were concatenated into a data file and analyzed as follows. First, reference profiles were obtained by averaging the intensity profiles for $20-50$ frames before the first voltage step. To measure the bundle movement in each successive frame, the reference profiles were shifted along the distance axis to minimize the difference between them and the corresponding intensity profiles of that frame (Fig. $1 B$ ). This was accomplished by linearly interpolating between the values of the reference profiles' pixels to obtain a "shifted" set of reference points to compare with each frame. An error value was calculated as the sum of the squares of the differences between corresponding points in that frame and the shifted reference profile. The Newton-Raphson method was used to converge rapidly to the minimum error. The technique afforded excellent spatial resolution (about $4 \mathrm{~nm}$ ) due to the bundle's high contrast under DIC optics. However, temporal resolution was limited by the $30 \mathrm{~Hz}$ video rate and the lag in the camera's phosphor. To estimate the delay introduced by the camera, the stimulus probe was driven with a known waveform that matched the predictions of the theory, and the actual probe movement was verified by a continuous photodiode measurement. The recorded movement was then analyzed using the automated routine. When movements were slow the video analysis was reasonably accurate: an exponential probe movement with a time constant of $104 \mathrm{msec}$ was measured as $111 \mathrm{msec}$. However, a $19 \mathrm{msec}$ exponential movement was measured as $43 \mathrm{msec}$. These delays must be considered when comparing observed bundle movement to theory.

Voltage-dependent bundle movement was usually superimposed on a slowly drifting baseline (less than $5 \mathrm{~nm} / \mathrm{sec}$ ). This may have been due to gradual shrinkage of the cell as it filled with the hypo-osmotic pipette solution, because it occurred primarily during the first few minutes of recording. Drift was compensated by subtracting the movement record of the base of the bundle from that of the tip.

\section{Theory}

In this section we develop a simple, quantitative theory for adaptation, based on an active "motor" element.

\section{Assumptions}

The first assumption of the theory is that tension in the elastic "gating springs" solely determines the open probability of transduction channels (Corey and Hudspeth, 1983b). Although there is some indication from a mechanical "rebound" that $\mathrm{Ca}^{2+}$ may in addition directly affect the probability (Howard and Hudspeth, 1988; Jaramillo et al., 1990), such effects have not yet been observed in our preparation of hair cells, and are not included in the model. Thus, adaptation, which is characterized as a shift in the $I(X)$ curve, is viewed in this theory as a change in tension on the transduction channels.

We assume, second, that the gating springs can pull but not push on the channels, based on asymmetries in the kinetics of the transduction current (Corey and Hudspeth, 1983b) and on an apparent decline in bundle stiffness for large negative displacements (Howard and Hudspeth, 1988). In further support of this assumption is evidence that tip links convey tension to the channels (Assad et al., 1991), since their filamentous struc-
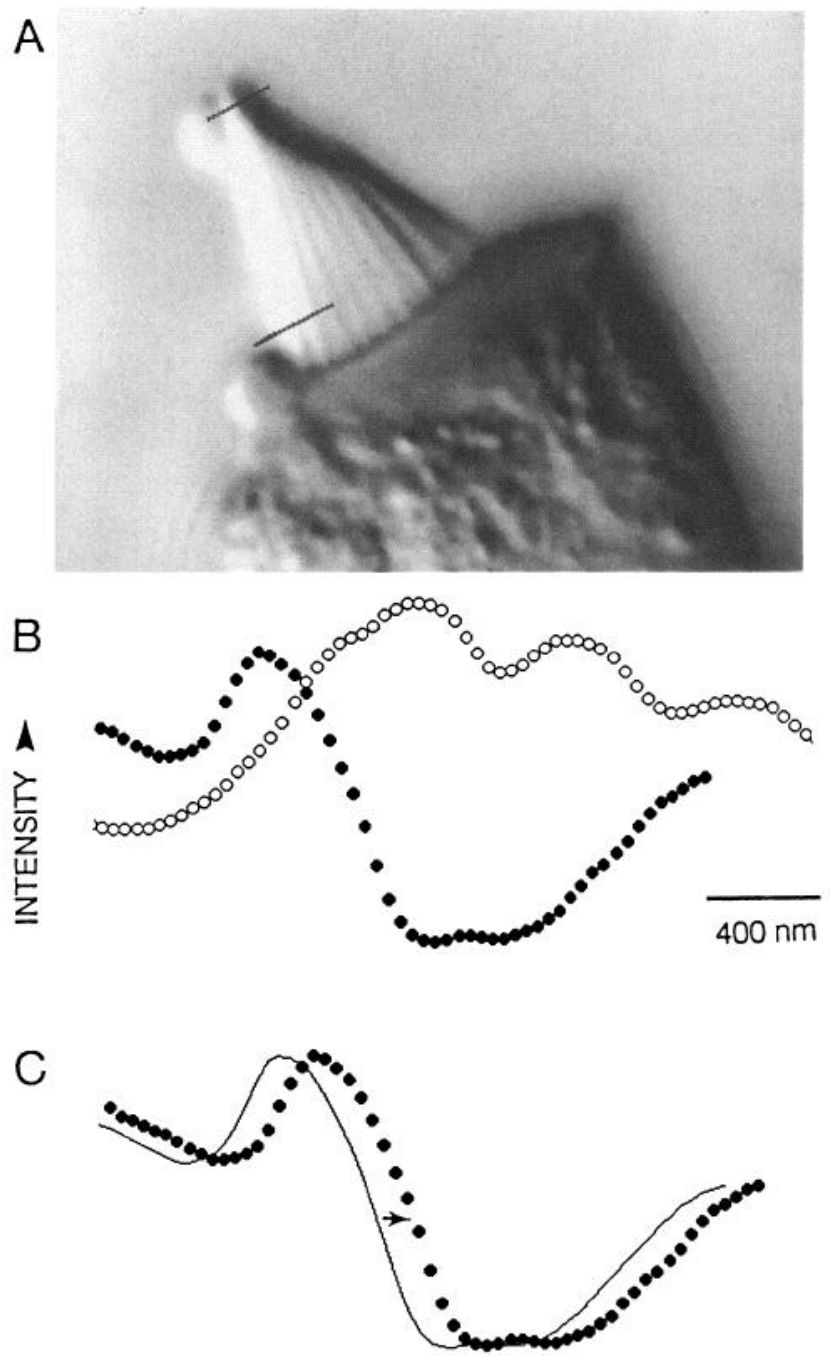

Figure 1. Measurement of active bundle movement. A, The position of the stereocilia was quantified from the video images by measuring the intensity profiles of several lines of pixels arrayed perpendicular to the long axis of the bundle (lines). B. The solid symbols represent the intensities of the line of pixels at the tip of the bundle in $A$, while the open symbols represent the line near the base. $C$, A reference profile was initially obtained for each line of pixels; the continuous line is the reference for the tip profile. An automated routine then measured the movement by shifting each reference profile (arrow) to minimize its difference with the intensity profile (solid symbols) for each frame.

ture appears incompatible with exertion of compressive force (Pickles et al., 1984).

Third, we take as a starting point the view of Howard and Hudspeth (1987; Hudspeth, 1985), in which gating spring tension is regulated by an active force generator, what we refer to as the "adaptation motor." In this model, the motor continually attempts to increase tension on the gating springs (Fig. $2 A$ ). The springs' restoring force in turn causes the motor to slip; a steady state is achieved when the rates of tensioning and slipping are balanced. When the bundle is displaced positively, the gating springs are stretched causing a proportional increase in slipping rate. When the gating springs are slackened by sufficient negative displacements, the motor tightens at a slower rate. Following maintained bundle displacements, the steady-state tension is reestablished at the new bundle position. Howard and Hudspeth suppose that the tension adjustment corresponds to movement 
of the upper tip link attachments along the sides of the stereocilia (Fig. 2A), a specific morphological model which has some support (Shepherd et al., 1991). However, the model and experiments in this report do not depend on any particular structural correlate of adaptation.

\section{A quantitative description}

We can extend this qualitative model by providing a mathematical description of the motor, which allows the hypothesis to be tested quantitatively. In the generalized mechanical diagram of Figure $2 B$, the bundle is represented as two elastic elements: the lumped gating springs and the intrinsic stiffness of the stereocilia, possibly representing the narrow tapers about which the stereocilia pivot. Contributions of individual stereocilia can be added together, because the sliding adhesion of their tips puts them mechanically in parallel (Corey et al., 1989; Jacobs and Hudspeth, 1990). The gating spring is in series with an active motor, which exerts force but can slip when under tension. The motor element could be represented in mechanical terms as a force source in parallel with a dashpot. In addition, the ability of the gating spring to become slack is incorporated as a "decoupler" that disconnects the gating spring when the force in it is less than zero. Finally, viscous drag and friction on the bundle are lumped into a single dashpot element in parallel with the stereocilia spring. The system is perturbed by changes in force, either exerted by the motor or applied externally to the bundle. The external input depends on the particular experiment, but is represented by the "probe" spring.

To retain generality, distances and forces are specified as parallel to the lateral displacement of the stereocilia, measured at the height of the kinociliary bulb. To determine tension and displacements in individual tip links, in that model for transduction, the variables should be scaled by the geometry factor $\gamma$, and by the number of channel/motor units $N$ (see Discussion).

The tension $T$ in a simple spring is the product of its spring constant $K$ and its displacement from rest position $X$, so

$$
T_{s}=K_{s} X_{s}, \quad T_{s}=K_{s} X_{s}, \quad T_{p}=K_{p} X_{p},
$$

where the subscripts $g, s$, and $p$ refer to gating, stereocilia, and probe springs, respcctivcly. The adaptation motor is assumed to be in series with the gating spring; tensioning is indicated by an increase in the position of the motor, $X_{m}$. Accordingly, the stretch of the gating spring is a combination of the bundle position and the motor position:

$$
X_{g}=X_{s}+X_{m}
$$

We have not included in this model the change in gating spring length that occurs with opening and closing of the channel.

The elongation or deflection of the probe spring, $X_{p}$, is the difference between the displacement applied to the probe spring, $X_{d}$, and the movement of the bundle:

$$
X_{p}=X_{d}-X_{s} \text {. }
$$

At rest or when bundle damping is negligible, the forces exerted by the springs must balance:

$$
T_{p}=T_{g}+T_{s},
$$

so the position of the bundle is

$$
X_{s}=\left(K_{p} X_{d}-K_{g} X_{m}\right) /\left(K_{p}+K_{s}+K_{g}\right) .
$$

To measure the transduction current, we always presented displacement steps to the bundle. The probe was much stiffer than
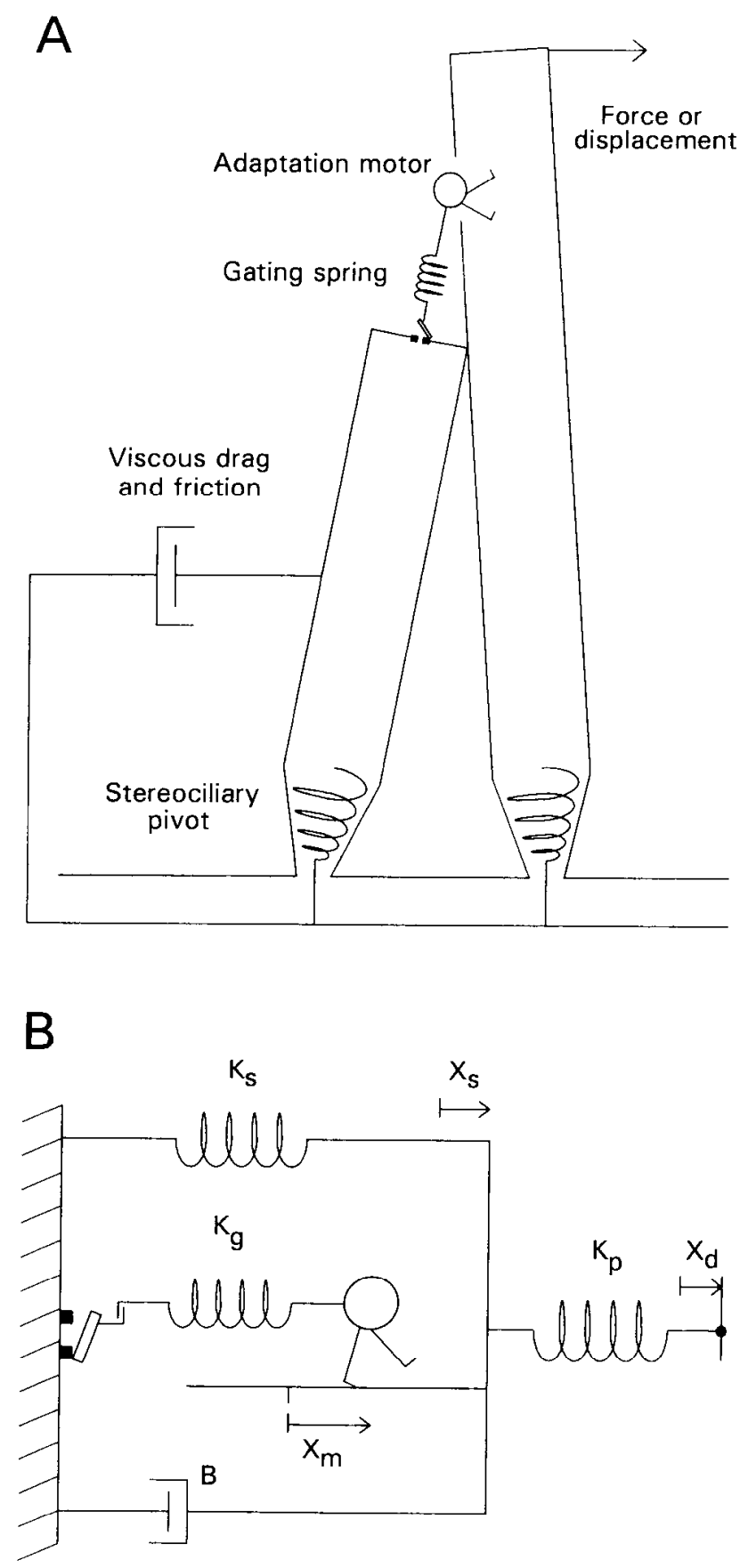

Figure 2. Mechanical equivalent of the bundle. A, A specific model in which the mechanical elements are superimposed on the stereociliary bundle (modified from Howard and Hudspeth, 1987). For this drawing, the gating springs are equated with the tip links; a separate elasticity is embodied in the stereociliary pivots. The motor is placed at the top of the tip link. $B$. A general representation to show the various mechanical elements relative to the motor. In this representation, all distances are relative to the lateral displacement of the bundle, at the level of the kinociliary bulb, in order to compare them to the stimuli presented. $X_{m}$ is the position of the motor relative to its substrate, $X_{s}$ is the displacement of the stereocilia, with stiffness $K_{s} . X_{g}$ is the stretch of the gating spring, with stiffness $K_{g} . X_{p}$ is the stretch of the probe spring, with stiffness $K_{p} . X_{d}$ is the displacement applied to the probe spring, which is in series with the bundle, so $X_{p}=X_{d}-X_{s}$. $B$ is the lumped damping coefficient on the bundle. The inability of the gating spring to exert force in compression is represented as a "decoupler," to the left of the gating spring. The stereociliary and gating springs are perceived as acting in parallel by external forces applied to the bundle, but are perceived in series by the motor. 
the parallel combination of stereocilia and gating springs; that is, $K_{p} \gg K_{s}+K_{g}$, thus $X_{s}=X_{d}$. In experiments to observe active motion of the bundle, it was unconstrained by a probe, so $K_{p}=0$ and $X_{s}=-X_{m} K_{g} /\left(K_{s}+K_{g}\right)$.

\section{Movement of the motor following bundle displacement}

The motor position $X_{m}$ is not directly observable in these experiments, nor is the stretch of the gating spring $X_{g}$. The observable variables are the bundle position $X_{s}$, controlled by the stimulus probe or measured directly with video microscopy, and the transduction current $I$, recorded with the patch clamp. Because the transduction current is a function of gating spring tension, $T_{g}=K_{g} X_{g}$, it can be used to infer $X_{g}$. With $X_{g}$ and $X_{s}$, then, the motor position $X_{m}$ can be determined.

Specifically, the change in $X_{m}$ is determined as a shift of the $I\left(X_{s}\right)$ curve along the $X_{s}$ axis. A series of brief bundle displacements was given to the cell, and the initial transduction current-measured before adaptation could occur-was measured for each. The position of this $I\left(X_{s}\right)$ curve represents the resting extension of the gating spring $X_{g}$. A maintained displacement of the bundle caused a shift in the position of the observed $I\left(X_{s}\right)$ curve. Since the tension dependence of the channels $I\left(X_{g}\right)$ is assumed to be fixed, and since $X_{g}=X_{s}+X_{m}$, a shift along the $X_{s}$ axis would equal the change in motor position, $-\Delta X_{m}$. Note that this procedure gives only changes in $X_{m}$ and $X_{g}$, not their absolute values.

The rate of change of $X_{m}$ is determined simply by measuring the shift in the $I\left(X_{s}\right)$ curve, at various times after a maintained bundle displacement (Assad et al., 1989; Hacohen et al., 1989). The initial rate of shift $R$ is defined as

$$
R=\frac{d(\text { shift })}{d t}=-\frac{d X_{m}}{d t} \quad \text { at } t=0 ;
$$

it represents how quickly the motor moves before it has moved very far. This was plotted against bundle position to generate an $R\left(X_{s}\right)$ curve. As previously noted (Hacohen et al., 1989), the $R\left(X_{s}\right)$ curve shows two distinct regions: for positive displacements, $R$ depends linearly on $X_{s}$; for large negative displacements, however, the initial rate had a constant, displacementindependent value. We interpret the breakpoint in the $R\left(X_{s}\right)$ curve as representing the point where the gating spring hecomes slack, that is, where $X_{g}=0$. Then, the movement of the motor can be described by different expressions depending on whether $X_{x}>0$ :

$$
\frac{d X_{m}}{d t}=C-S X_{g} \quad\left(X_{g} \geq 0\right)
$$

and

$$
\frac{d X_{m}}{d t}=C \quad\left(X_{g}<0\right) .
$$

$C$ is a displacement-independent climbing rate; it is equal to $-R\left(X_{s}\right)$ for large negative displacements. $S$ is the slope of the $R\left(X_{s}\right)$ curve for positive displacements; it is a rate constant so that slipping is proportional to stretch of the gating spring, $X_{z}$.

$R\left(X_{s}\right)$ was defined, and the parameters $S$ and $C$ determined, at $t=0$. Assuming Equation 2 holds for longer times, it can be solved to give the motor's approach to steady state. Following a displacement step (such that $X_{g}$ remains $>0$ ),

$$
X_{m}(t)=(C / S)-X_{s}[1-\exp (-t S)] .
$$

The motor would move-and the $I\left(X_{s}\right)$ curve shift-with an exponential time course. The time constant is $1 / S$.

\section{Tension in the gating spring at steady state}

For any bundle position, the motor reaches a steady-state position when the climbing rate $C$ is equal to the slipping rate $S X_{z}$. That is, $d X_{m} / d t=0$ when $X_{g}=C / S$. Thus, at steady state there is a resting extension of the gating spring, and a resting tension of $T_{g}=K_{g} X_{g}=K_{g} C / S$. A negative displacement $X_{s}=-C / S$ is required to make it slack. This is a result, of course, of interpreting the breakpoint in the $R\left(X_{s}\right)$ curve as the slack point.

An interesting consequence is that an unconstrained bundle would be pulled in the negative direction by this resting tension. With no stimulus probe, $X_{s}=-X_{m} K_{g} /\left(K_{s}+K_{g}\right)$ from Equation 1. Since $X_{m}=X_{g}-X_{s}$, the displacement of an unconstrained bundle is

$$
X_{s}=-(C / S)\left(K_{g} / K_{s}\right)
$$

One prediction is that if the gating spring were cut, leaving only the stereocilia spring in the model, the bundle would move forward by this amount.

\section{Movement of the motor with voltage steps}

The parameters $S$ and $C$, which describe the $R\left(X_{s}\right)$ curve, are functions of the $\mathrm{Ca}^{2+}$ concentration in the bath (Hacohen et al., 1989). As shown in the Results, they are functions of membrane potential as well. We assume here that $S$ and $C$ are instantaneous functions of membrane potential. Physiologically, this implies that the "adaptation site" for $\mathrm{Ca}^{2+}$ equilibrates rapidly when $\mathrm{Ca}^{2+}$ entry into a stereocilium is altered; the assumption is supported by the observation that the rate of adaptation to a positive displacement increases very rapidly upon hyperpolarization from +80 to $-80 \mathrm{mV}$ (Assad et al., 1989). When the bundle position is constrained $\left(X_{s}=0\right)$, the motor position $X_{m}$ following a voltage step is

$$
X_{m}(t)=(C / S)+\left(C_{0} / S_{0}-C / S\right) \exp (-t S),
$$

where $S$ and $C$ are the constants at the new voltage and $S_{0}$ and $C_{0}$ are the constants before the voltage step.

Shift of the $\mathrm{I}\left(\mathrm{X}_{\mathrm{s}}\right)$ curve. Equation 5 indicates that the motor moves a distance $\left(C / S-C_{0} / S_{0}\right)$ in response to a voltage step. Thus, a second prediction is that the $I\left(X_{s}\right)$ curve will shift negatively by this amount. The time course of the shift is determined solely by the time constant at the new voltage, which is $1 / S$ when the bundle is constrained.

Movement of the bundle. For an unconstrained bundle, $X_{g}=$ $X_{m} K_{s} /\left(K_{s}+K_{g}\right)$. Substituting into Equation 2 gives

$$
\frac{d X_{m}}{d t}=C-S X_{m}\left(\frac{K_{s}}{K_{g}+K_{s}}\right)
$$

Assuming that the movement of the bundle instantaneously follows that of the motor, that is, that drag is negligible, this can be solved to give the time course of the bundle position in response to a voltage step:

$$
X_{s}(t)-\frac{K_{g}}{K_{s}}\left\{\frac{C}{S}+\left(\frac{C_{0}}{S_{0}}-\frac{C}{S}\right) \exp \left[-t S \frac{K_{s}}{K_{g}+K_{s}}\right]\right\} \text {. }
$$

The model thus makes a third prediction: the change in gating spring tension with voltage will move an unconstrained bundle 
to a new rest position. The change in bundle position with voltage at steady state is

$$
\Delta X_{s}=-\left(\frac{C}{S}-\frac{C_{0}}{S_{0}}\right) \frac{K_{g}}{K_{s}} .
$$

The stiffness of the gating spring is approximately 0.8 that of the stereocilia (Howard and Hudspeth, 1987, 1988). Thus, following a voltage step, an unrestrained bundle should move by slightly less than the distance that the $I\left(X_{s}\right)$ curve shifts if the bundle is fixed.

The predicted time course of the movement is again an exponential relaxation, with a time constant that depends on the new potential, but the time constant is increased by a factor of $\left(K_{z}+K_{s}\right) / K_{s} \simeq 1.8$, commensurate with the increased compliance of the two springs in series.

\section{Effect of damping}

The dynamics of the active movement would be slowed by drag and friction on the bundle. In the model, these influences are lumped into a single dashpot with damping coefficient $B$. Damping can be disregarded for displacement steps or at rest; however, it must be considered when examining the response to a force probe or the active movements of an unconstrained bundle. The force exerted by the dashpot is proportional to the velocity of the bundle, $d X_{s} / d t$, and the sum of the forces must balance. Thus (with $X_{g}>0$ ),

$$
B \frac{d X_{s}}{d t}+K_{s}\left(X_{m}+X_{s}\right)+K_{s} X_{s}=K_{p} X_{r} .
$$

When there is no stimulus probe $\left(K_{p}=0\right)$, the position of the bundle is given by the differential equations

$$
\frac{d X_{s}}{d t}=-\frac{1}{B}\left[K_{s} X_{m}+\left(K_{s}+K_{s}\right) X_{s}\right]
$$

and

$$
\frac{d X_{m}}{d t}=C-S\left(X_{s}+X_{m}\right)
$$

The solution yields a two-exponential relaxation, with time constants equal to

$$
\tau_{1.2}=2 B /\left\{S B+K_{g}+K_{s} \pm \sqrt{\left(S B+K_{g}+K_{s}\right)^{2}-4 S B K_{s}}\right\}
$$

In the limit as $B$ approaches 0 , the solution collapses to a single time constant, $\tau=\left(K_{g}+K_{s}\right) / S K_{s}$, as expected for an unconstrained bundle without damping (Eq. 6).

\section{Number of intact motor units}

The tip links hypothesis for transduction supposes that the gating springs are discrete units, each perhaps controlled by a separate motor (Fig. 1A). Accordingly, the number of functional motor/gating-spring units should also influence the extent of active movement, inasmuch as the motors are expected to function in parallel in exerting tension on the bundle. The lumped gating spring constant defined by Howard and Hudspeth (1987) would then be the sum of $N$ discrete gating springs, each with stiffness $k_{g}$ (as measured with bundle deflections), so $K_{g}=N k_{g}$. Similarly, if $i$ is the amplitude of the transduction current elicited by a single, intact gating spring, the whole-cell transduction current reflects the number of elements: $I=N i$. Reduction in
$N$, for instance by tip link breakage, would reduce $K_{g}$ and $I$ proportionally. However, reduction in $N$ would not reduce the number of stereocilia and they would continue to act in parallel, so $K_{s}$ remains constant. The active movement

$$
\Delta X_{s}=-\left(\frac{C}{S}-\frac{C_{0}}{S_{0}}\right) \frac{K_{g}}{K_{s}}=-\frac{I}{i}\left(\frac{C}{S}-\frac{C_{0}}{S_{0}}\right) \frac{k_{g}}{K_{s}} .
$$

Thus, the bundle movement elicited by voltage steps will be proportional to the transduction current, other factors being equal. This offers another test of the model.

\section{Results}

\section{The $\mathrm{R}\left(\mathrm{X}_{s}\right)$ curve at two potentials}

The theory presented above is based primarily on the rates derived from the $R\left(X_{s}\right)$ curve. Because the $R\left(X_{s}\right)$ curves of $\mathrm{Ha}$ cohen et al. (1989) were obtained using an in vitro microphonic preparation that did not afford control of mcmbrane potential, it was first necessary to determine the $R\left(X_{s}\right)$ relation in isolated, voltage-clamped hair cells. $R\left(X_{s}\right)$ curves were determined at both -80 and $+80 \mathrm{mV}$ using the step protocol of Eatock et al. (1987) and Hacohen et al. (1989) (Fig. 3). It was extremely rare to record stably from a single cell long enough to obtain a complete data set at both -80 and $+80 \mathrm{mV}$; accordingly, the $R\left(X_{s}\right)$ curves of Figure $3 D$ represent combined data from 26 cells.

At both -80 and $+80 \mathrm{mV}$, the rate of adaptation increased approximately linearly with displacement in the positive direction, at least for displacements up to about $500 \mathrm{~nm}$. A saturation of the rate with larger displacements was consistently obscrved at $-80 \mathrm{mV}$ in normal $4 \mathrm{~mm} \mathrm{Ca}^{2+}$, similar to that observed by Hacohen et al. (1989) for high $\mathrm{Ca}^{2+}$ concentrations. In some but not all cells the $I(X)$ curve broadened as it shifted. It is possible that this effect may have caused a systematic underestimation of the rate for large displacements; however, most of the cxperiments described below involved only small shifts of the $I\left(X_{s}\right)$ curve, within the range of the $R\left(X_{s}\right)$ curve where there was little broadening. The slope of the $R\left(X_{s}\right)$ curve for positive displacements was much greater at -80 than $+80 \mathrm{mV}$. The first four points of the $R\left(X_{s}\right)$ curve were fitted by a straight line using least-squares analysis with the constraint that the line intercept the origin. The average slope was $80.8 \mathrm{sec}^{1}$ at $-80 \mathrm{mV}$ and $15.4 \mathrm{sec}$ ' at $+80 \mathrm{mV}$. For negative steps the rate of adaptation became essentially independent of displacement at positions more negative than about $-0.2 \mu \mathrm{m}$. This was true at both membrane potentials. The rate averaged over the three largest negative displacements was less at the depolarized potential: 4.9 $\mu \mathrm{m} \mathrm{sec}{ }^{-1}$ at $+80 \mathrm{mV}$ compared to $15.7 \mu \mathrm{m} \mathrm{sec}{ }^{1}$ at $-80 \mathrm{mV}$.

These rates were determined by an exponential fit to the shift of the $I\left(X_{s}\right)$ curve, for step displacements of $20 \mathrm{msec}$ duration. If rates are constant, the timc coursc of the shift should be exponential over longer times. The time course previously reported for 100 msec step displacements (Assad et al., 1989) was roughly exponential, and had an average time constant of 13.8 msec, compared to the predicted time constant of $1 / S=12.4$ msec.

\section{Shift of the $\mathrm{I}\left(\mathrm{X}_{3}\right)$ curve with voltage}

The position of the $I\left(X_{s}\right)$ curve is determined by the steadystate motor position, which is $X_{m}=C / S$ when $X_{s}$ is held at 0 . At $-80 \mathrm{mV}, C / S=194 \mathrm{~nm}$, while at $+80 \mathrm{mV}, C / S=318 \mathrm{~nm}$; 
A
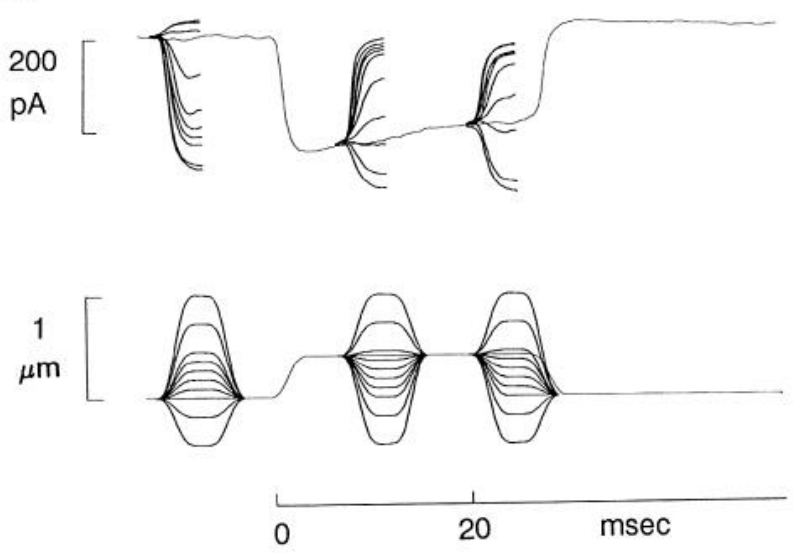

B
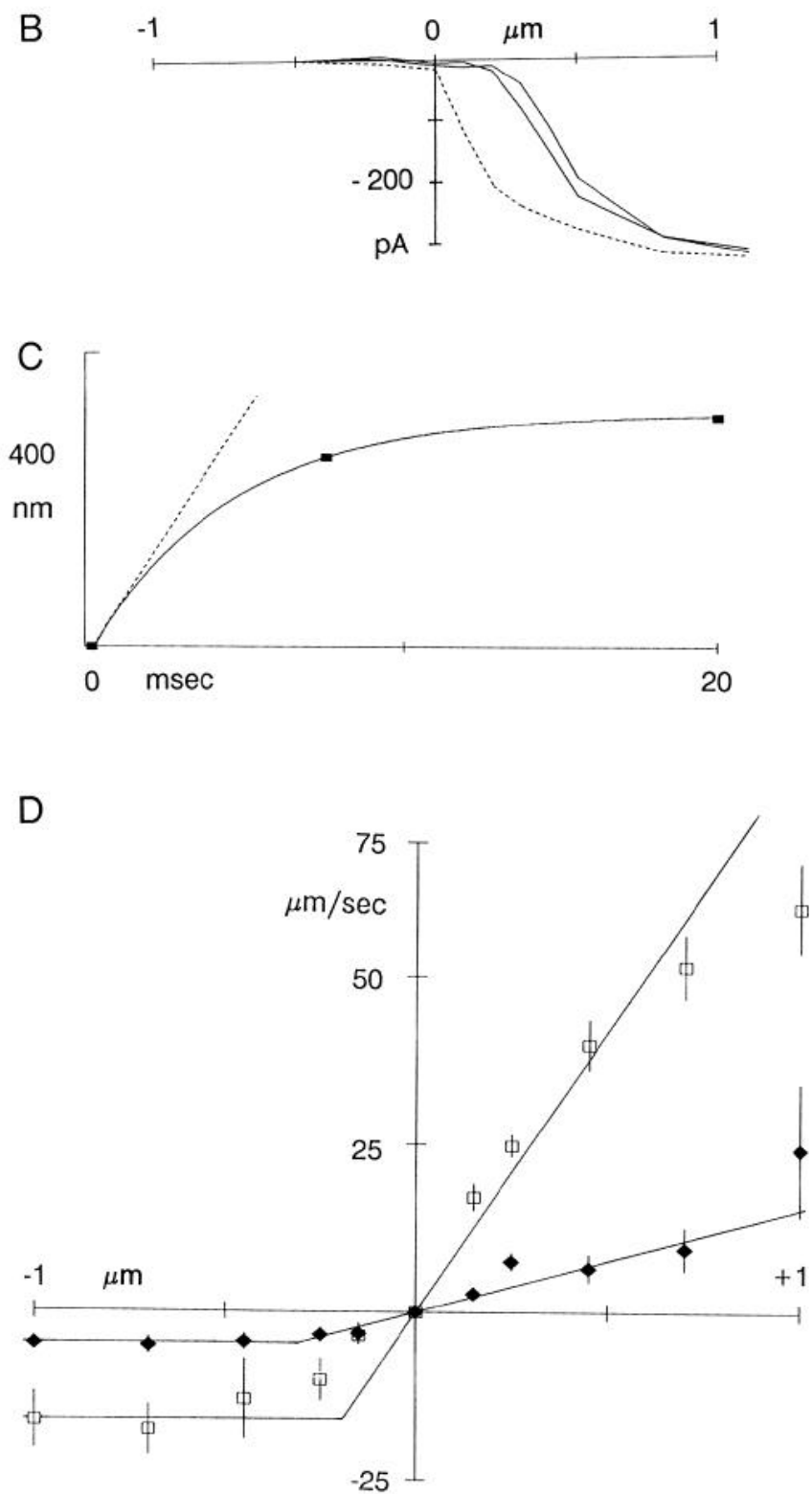

Figure 3. Step protocol for determining the $R\left(X_{s}\right)$ curve in an isolated, voltage-clamped hair cell. $A$, Transduction current (top trace) was elicited by the displacements shown in the bottom trace. Each stimulus thus, the $I\left(X_{s}\right)$ curve should shift negatively by $124 \mathrm{~nm}$ upon depolarization. In Figure 4, the voltage-dependent $I\left(X_{s}\right)$ shift was analyzed, on depolarization from -80 to $+80 \mathrm{mV}$ (Fig. $4 A$ ), and then in separate experimental runs on repolarization from +80 to $-80 \mathrm{mV}$ (Fig. $4 C$ ). The protocol was similar to that used to determine the $R\left(X_{s}\right)$ curve, except that the shift was measured following a voltage step rather than a displacement step. The shifts of the $I\left(X_{s}\right)$ curve are plotted as a function of time in Figure 4, $B$ and $D$. The shift on depolarization was fitted by two exponentials with a total amplitude of $-124 \mathrm{~nm}$ (leftward). The movement of the $I\left(X_{s}\right)$ curve following repolarization from +80 to $-80 \mathrm{mV}$ had an amplitude of $141 \mathrm{~nm}$. The results from this cell are typical of all cells examined in this manner. For 11 separate runs, the average was $139 \pm 40 \mathrm{~nm}$ (mean \pm $\mathrm{SD}$ ), which is reasonably close to the predicted $124 \mathrm{~nm}$.

The approach to the new position should be exponential with a time constant equal to $1 / S$ at the new voltage. Thus, following a step from -80 to $+80 \mathrm{mV}$, the time constant should be 65 msec; the shift on repolarization to -80 should proceed with a time constant of $12 \mathrm{msec}$. For the cell of Figure 4, the shift with depolarization could not be fitted well by a single exponential function, but required a sum of two exponentials with time constants of 6 and $64 \mathrm{msec}$. In this cell the return on repolarization had a single time constant of $9 \mathrm{msec}$.

The average time course was determined by calculating the $I\left(X_{s}\right)$ shift at each time point as a percentage of the maximum shift for each cell. The averaged data were plotted and fitted with a smooth curve in Figure $4 E$. On depolarization to +80 $\mathrm{mV}$ the $I\left(X_{s}\right)$ curve shifted as the sum of two exponentials with time constants of 4 and $61 \mathrm{msec}$, and amplitudes of $46 \%$ and $54 \%$ of maximum, respectively. The average time course following return to $-80 \mathrm{mV}$ was fitted well by a single exponential with a time constant of 9 msec.

The preceding experiments measured the shift of the $I\left(X_{s}\right)$ curve at discrete time points following a voltage step. The shift could also be monitored indirectly, but with higher temporal resolution, by recording the current though the transduction channels. The leftward shift of the $I\left(X_{s}\right)$ curve with depolarization increases the open probability at rest; thus, we expect an

\footnotetext{
presentation consisted of a $450 \mathrm{~nm}$ displacement maintained for 20 msec, and a single $5 \mathrm{msec}$ test step at one of three times. This protocol was repeated at $300 \mathrm{msec}$ intervals for each of 10 test stimulus amplitudes, at each time. $B, I\left(X_{s}\right)$ curves were constructed from the responses in $A$ by plotting the peak amplitude of each test current against the displacement that elicited it. The shift of the $I\left(X_{s}\right)$ curve at each time was measured by translating the resting $I\left(X_{s}\right)$ curve (broken curve)obtained before the maintained displacement was delivered-along the displacement axis to obtain a best fit by eye to the $I\left(X_{s}\right)$ curves obtained during the maintained displacement (solid curves). $C$, The shift of the $I\left(X_{s}\right)$ curve was plotted as a function of time and fitted with an exponential function. The initial rate of adaptation was taken as the initial slope of the curve (broken line). This entire procedure yielded a single point on the $R\left(X_{s}\right)$ curve: the initial rate corresponding to the $450 \mathrm{~nm}$ displacement in $A$. The same protocol was repeated over a range of maintained displacements, at both -80 and $+80 \mathrm{mV}$. $D$, Averaged $R\left(X_{s}\right)$ curves at -80 and $+80 \mathrm{mV}$. Data are plotted relative to the displacement of the bundle. Open symbols, $R\left(X_{s}\right)$ curve at $-80 \mathrm{mV}$; solid symbols, $R\left(X_{s}\right)$ curve at $+80 \mathrm{mV}$. Each point is the average rate among multiple cells: for the range of positive displacements at -80 $\mathrm{mV}$, initial rates from 14 cells were averaged, while for negative displacements at $-80 \mathrm{mV}$, four cells were averaged. At $+80 \mathrm{mV}$, results from four cells were averaged for both positive and negative displacements. Error bars are SEM.
} 

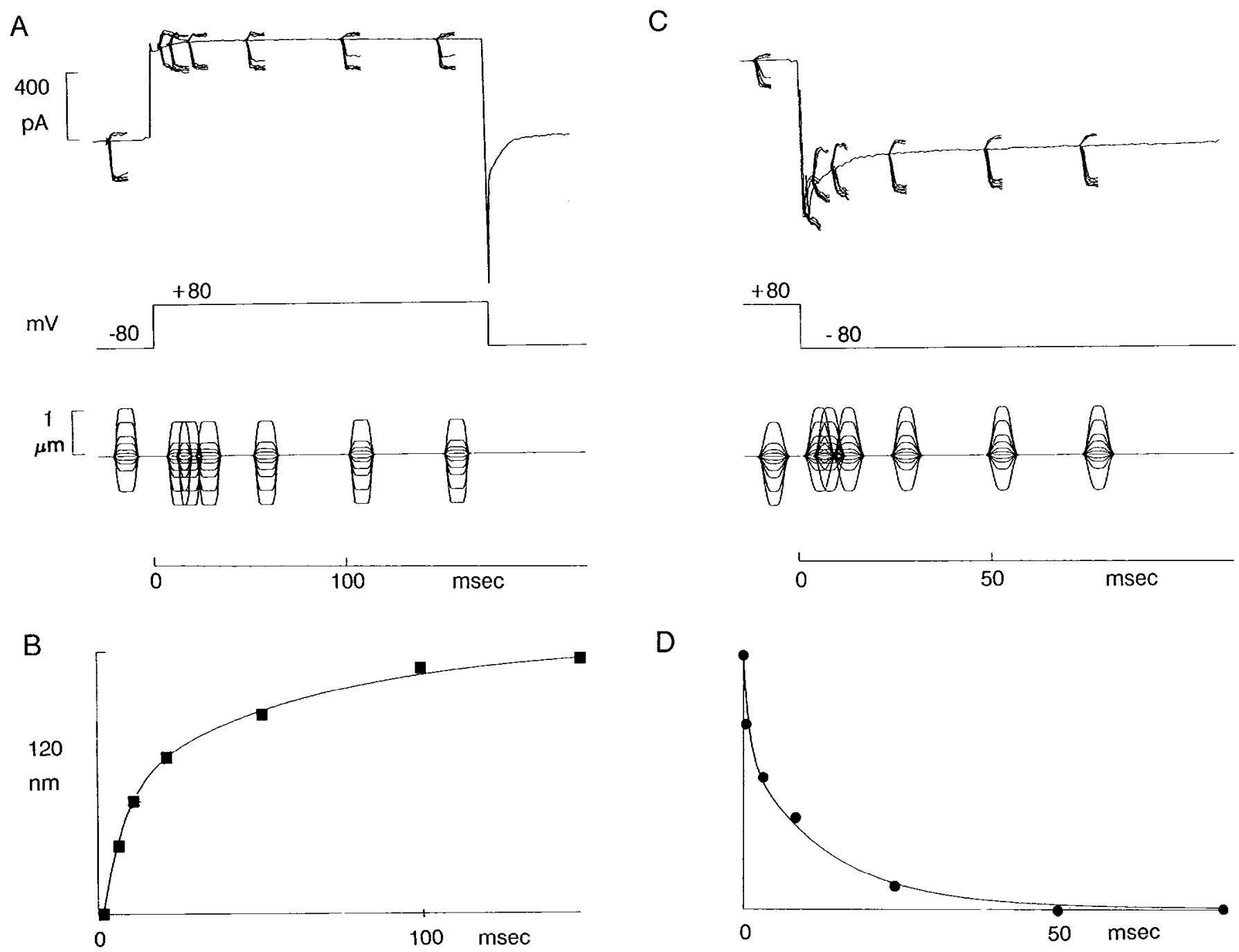

\section{$\mathrm{E}$}

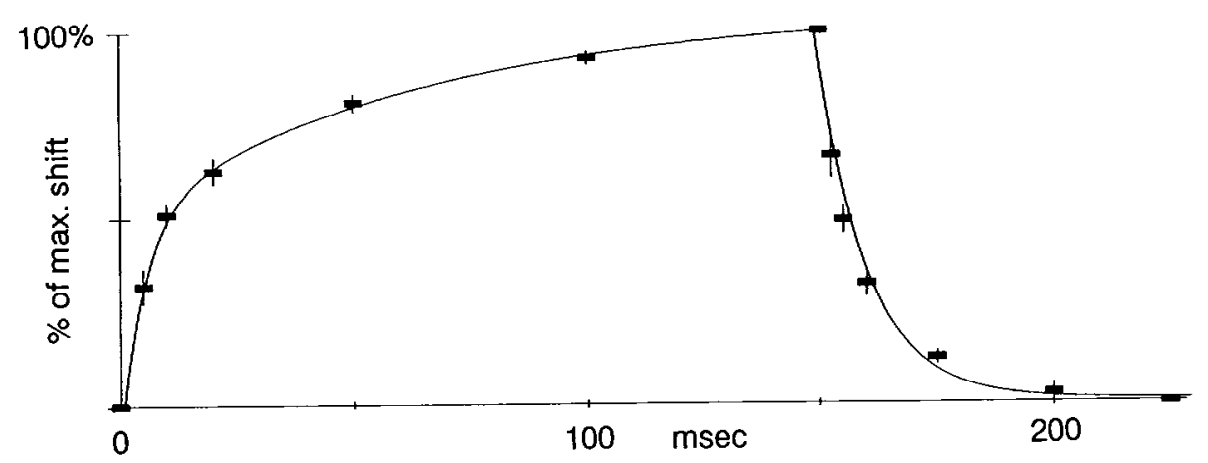

Figure 4. Protocol for determining the timecourse of shift of the $I\left(X_{s}\right)$ curve resulting from changes in membrane potential. $A$, Membrane current (top trace) elicited by the voltage and displacement stimulus (bottom traces). Each stimulus presentation consisted of a $150 \mathrm{msec}$ depolarization from -80 to $+80 \mathrm{mV}$ and a single $10 \mathrm{msec}$ bundle displacement delivered at one of seven test times. This protocol was repeated at 600 msec intervals for each of 10 test amplitudes, at each test time. The transduction current resulting from each test displacement was isolated by subtracting the background currents with no displacement stimuli. As in Figure $2, I\left(X_{s}\right)$ curves were generated at each test time, and the magnitude of shift of the $I\left(X_{s}\right)$ curve was measured by translating the resting $I\left(X_{s}\right)$ curve along the displacement axis. $B$, The shift of the $I\left(X_{s}\right)$ curve as a function of time; the smooth curve is the two-exponential fit to the data. $C$, Measurement of the time course of shift of the $I\left(X_{s}\right)$ curve determined for a voltage step from +80 to $-80 \mathrm{mV}$. The cell was depolarized to $+80 \mathrm{mV}$, for $150 \mathrm{msec}$ prior to the repolarizalion. $D$, The time course of shift back to baseline, fitted with a single exponential function. Note that the time scale is twice as fast in $D$ as in $B$. $E$, Time course of the shift of the $I\left(X_{s}\right)$ curve in response to a voltage step, averaged among multiple cells. For each cell, the degree of shift at each test time was calculated as a fraction of the maximum shift; data points are the average percentage of shift. Seven cells were averaged for depolarization to $+80 \mathrm{mV}$; four cells for hyperpolarization back to $-80 \mathrm{mV}$. Error bars are SEM. 
increase in outward current upon depolarization to positive potentials. This "shift" current was revealed by subtracting background currents using the protocol of Figure $5, A$ and $B$; the change in channel open probability is plotted in Figure $5 C$. The time course of the calculated probability agrees well with the previous measurement: the change with depolarization required two time constants, of 7 and $72 \mathrm{msec}$, and the return with hyperpolarization was fitted by a single exponential of $14 \mathrm{msec}$. Note that the time course of the probability is not identical to that of the shift of the $I\left(X_{s}\right)$ curve in Figure 3, because the open probability reflects the nonlinear $I\left(X_{s}\right)$ function and is thus not proportional to the position of the $I\left(X_{s}\right)$ curve.

Two controls indicated that the shift current actually represents the change in open probability of transduction channels, and not, for instance, another current activated by voltage-dependent calcium influx through open transduction channels. First, the voltage step was presented during large mechanical stimuli that either opened or closed all channels. Subtracting currents under the two conditions revealed a transduction current that had no time dependence. Thus, there was no slowly activating current that depended on open transduction channels. Second, the reversal potential of the shift current, measured from the current tail upon repolarization, was the same as that of the transduction current (data not shown; see Assad, 1991).

Determining the actual time course of the shift with this method would require that the shift current be deconvolved with the measured $I\left(X_{s}\right)$ curve. However, the method is experimentally simpler and offers better temporal resolution. Importantly, it illustrates that the transduction channels-while not directly gated by membrane potential-appear to open in a voltagedependent manner as a consequence of adaptation.

A surprising prediction of the adaptation model is that an unconstrained bundle should move when the cell is depolarized. Substituting the values of $S$ and $C$ from the $R\left(X_{s}\right)$ curve into Equation 6 yields an cxpccted steady-state movement of $99 \mathrm{~nm}$ when membrane potential is stepped from -80 to $+80 \mathrm{mV}$. Fquation 7 anticipates that the bundle motion will follow an exponential time course with a time constant equal to $117 \mathrm{msec}$ on depolarization to $+80 \mathrm{mV}$, and $22 \mathrm{msec}$ on return to -80 $\mathrm{mV}$. We used high-magnification video microscopy to look for voltage-dependent active bundle movement. Movement was an extremely reproducible phenomenon and was observed in over 60 cells. Responses elicited by 1 sec depolarizations were usually detectable by eye on the video monitor and were clearly stimulus locked (videotape available on request). In every case the movement was away from the kinocilium with depolarization to +80 $\mathrm{mV}$, and toward the kinocilium on hyperpolarization back to $-80 \mathrm{mV}$.

Video images acquired at +80 and $-80 \mathrm{mV}$ were digitally subtracted to reveal which parts of the bundle moved with depolarization (Fig. 6). The difference image was maximal ncar the tips of the stereocilia and declined to zero near the bases, indicating a pivoting of the stereocilia in the bundle. No voltagedependent movement of the soma or cuticular plate was visible in any cell. We estimate that movements of the cuticular plate of $10 \mathrm{~nm}$ would have been detectable with this method (Shepherd et al., 1991).

The time course and magnitude of the movement were analyzed by matching intensity profiles of segments of the image, as described in Materials and Methods. Figure $7 \mathrm{~A}$ shows some typical responses of bundles to a series of $1 \mathrm{sec}$ voltage steps
A
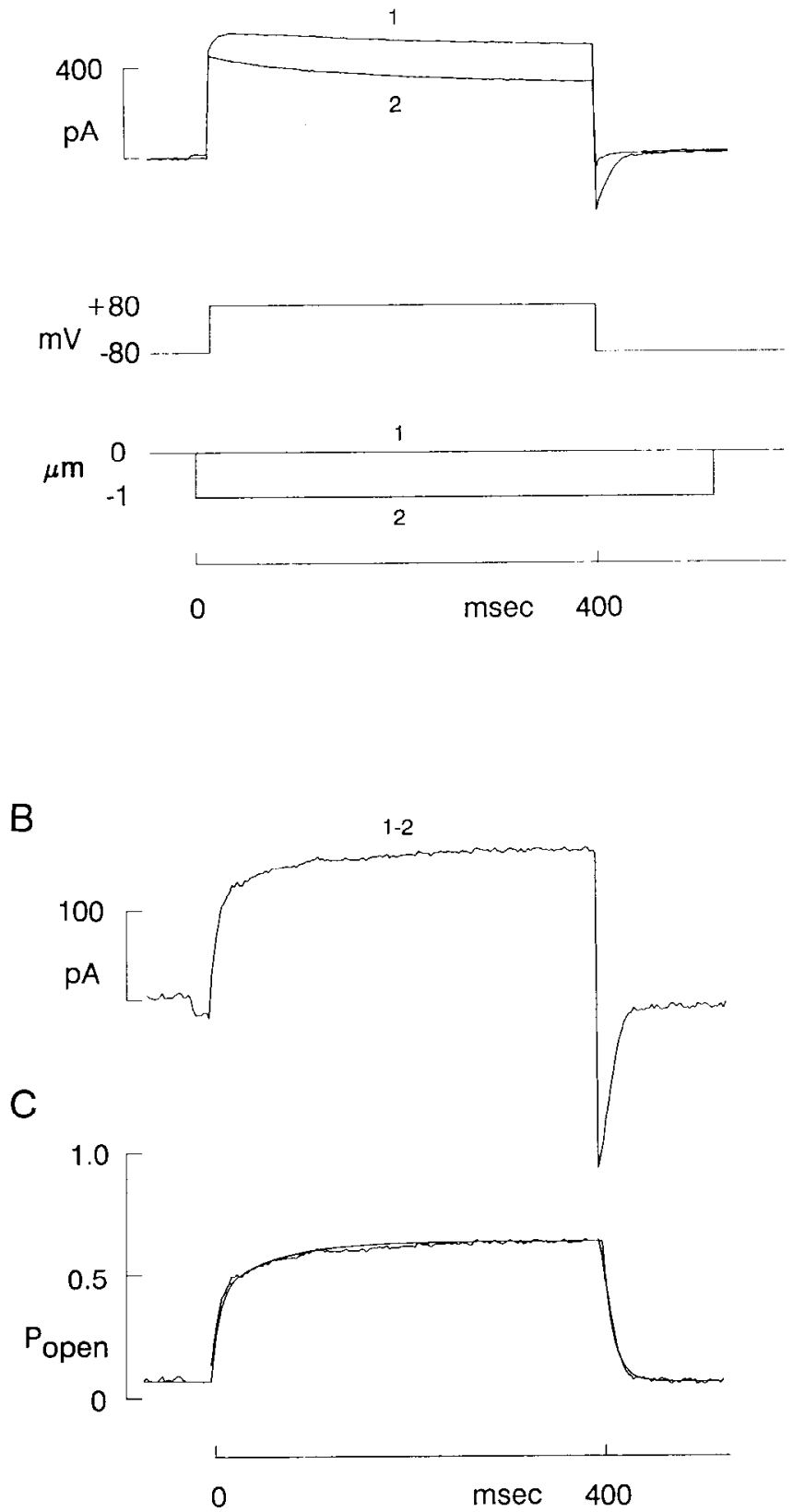

Figure 5. Increase in transduction current as a consequence of the $I\left(X_{s}\right)$ curve shift with depolarization. $A$, Membrane currents (top trace) elicited by the stimulus template (bottom traces). Trace $l$ is the sum of the currents through all channels including the transduction channels open at rest. Trace 2 shows the currents through all channels but the transduction channels, which had been closed by a saturating negative bundle displacement (trace 2 of the displacement stimulus). B, Trace 2 was subtracted from trace $l$ to yield the isolated transduction current. This "shift" current was outward on depolarization to $+80 \mathrm{mV}$, and inward on hyperpolarization back to $-80 \mathrm{mV}$. C. The change in transduction channel open probability was determined by normalizing the transduction current in $B$ against the peak-to-peak transduction current measured at both -80 and $+80 \mathrm{mV}$ just prior to this experiment. The time course of opening on depolarization was fitted with the sum of two exponential functions with time constants of 7 and $72 \mathrm{msec}$ and amplitudes of 0.35 and 0.22 , respectively. The time course following hyperpolarization back to $-80 \mathrm{mV}$ was fitted with a single exponential function with a time constant of $14 \mathrm{msec}$ and amplitude 0.57 . Over half the channels open as a consequence of the $I\left(X_{s}\right)$ shift. 
Figure 6. Voltage-dependent bundle motion. $A$, High-magnification video image of the bundle. The white bars are signals from the video bar-graph generator; the lower bar indicated the voltage command to the cell. $B$, Images at +80 and $-80 \mathrm{mV}$ were digitally subtracted to reveal bundle movements. No difference was assigned an intermediate gray level; contrast was enhanced by a factor of 2.5 .

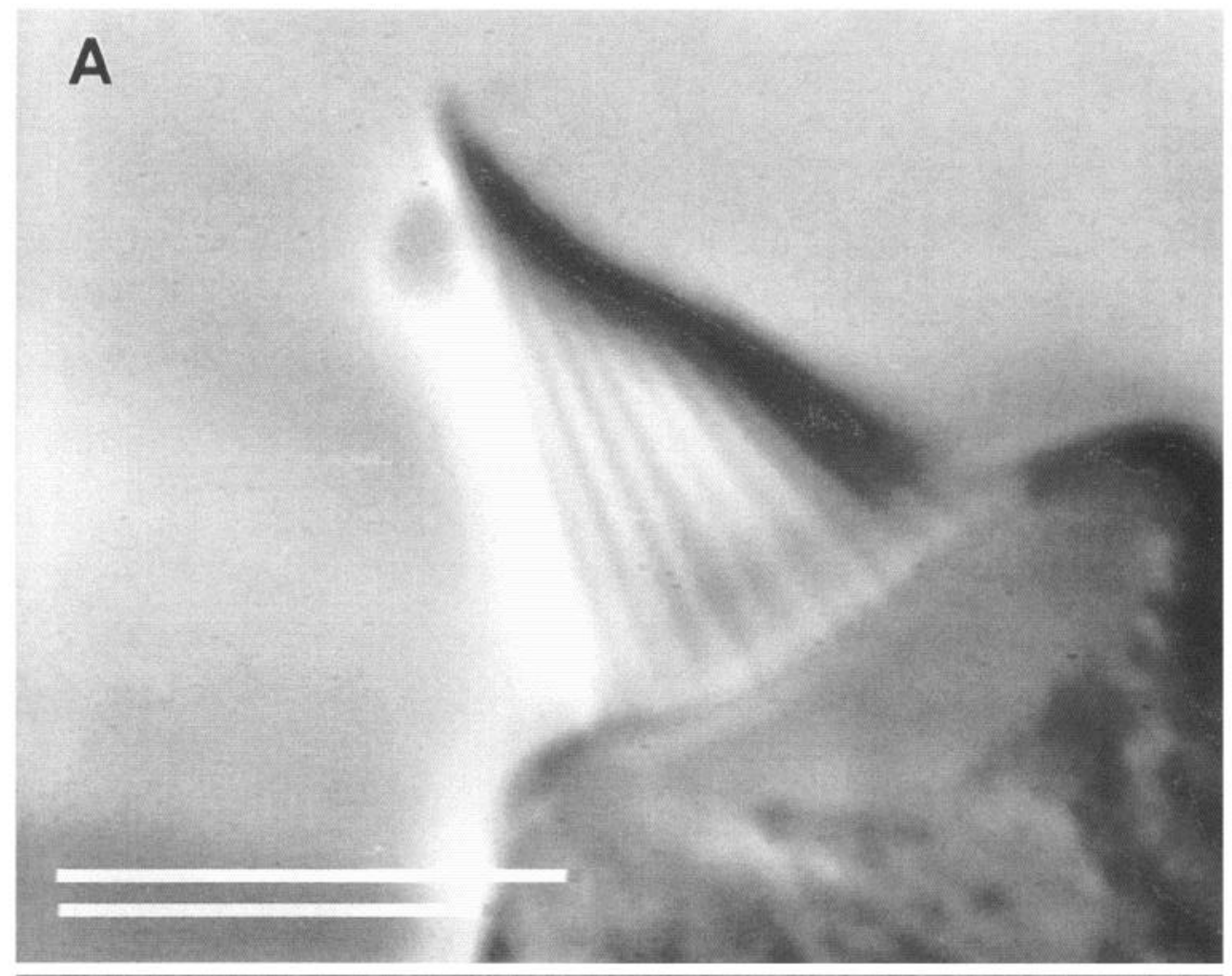

B

from -80 to $+80 \mathrm{mV}$. The average of 10 cycles for a single cell is shown in Figure $6 B$. The amplitude of the movement in this cell was $88 \mathrm{~nm}$, and both phases of movement could be fitted reasonably well with single exponentials. The time constants were 166 and $59 \mathrm{msec}$, respectively. In 41 out of 42 cells, the movement following the initial depolarization was slower than the return upon repolarization to $-80 \mathrm{mV}$. The average time constant of the negative movement following depolarization to $+80 \mathrm{mV}$ was $193 \pm 82 \mathrm{msec}( \pm \mathrm{SD} ; N=42)$; on return to -80 $\mathrm{mV}$ the average time constant was $56 \pm 24 \mathrm{msec}$. These rates were slower than anticipated, which may be due in part to drag on the bundle (see Discussion). However, the asymmetry between the two rates was unmistakable, even by inspection of the original videotape. 
A

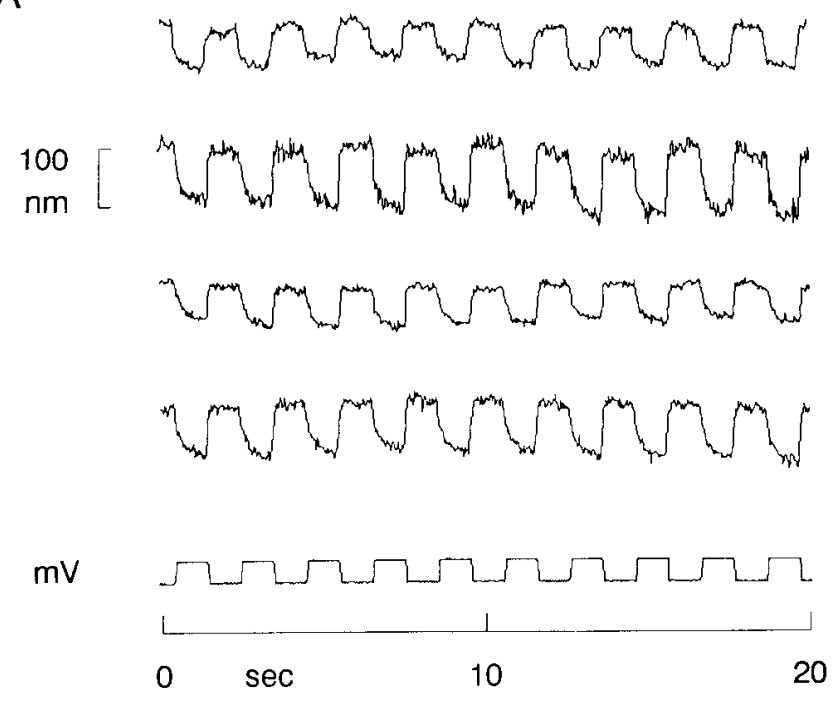

B

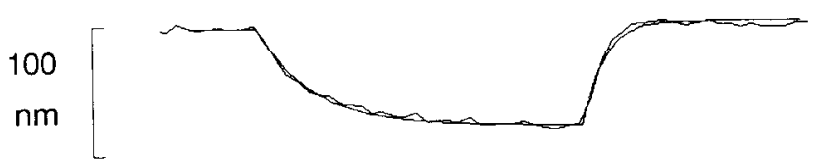

$0 \sec 12$

Figure 7. Voltage-dependent bundle movement. A, Examples of bundle movement quantified by shifting intensity profiles as in Figure 1 for four different cells. The stimulus in each case was a $1 \mathrm{sec}$ depolarization from $-80 \mathrm{mV}$ to $+80 \mathrm{mV}$, delivered at $2 \mathrm{sec}$ intervals. The negative bundle direction is downward in the figure. $B$, Average movement for the bottom cell in $A$. Ten cycles of movement were averaged. The backward deflection and forward relaxation were each fitted with a single exponential function.

The magnitude and time course of the movement were predicted with the assumption that all transduction elements are intact. However, as outlined in Theory, the size of voltagedependent bundle movement should depend on the amplitude of the transduction current. Bundle movement varied considerably among the 61 cells analyzed $(0-106 \mathrm{~nm})$, with an average of $50 \mathrm{~nm}$. For 24 of these cells, peak-to-peak transduction current was elicited with a saturating triangle-wave displacement of the bundle, by attaching to the bundle after measurement of active motion (Fig. 8). No bundle movement was observed in three cells that lacked discernible transduction current but displayed high input resistance and normal voltage-dependent currents. The amplitude of movement then increased with peak transduction current. The scatter in Figure 8 was large but asymmetric: cells with small transduction currents rarely showed appreciable movement, although several cells with large transduction currents also showed small movements. Thus, intact transduction appeared necessary, but not sufficient, for active bundle motion to occur. The scatter could also reflect variability in the amplitude of the $I\left(X_{s}\right)$ shift among cells, which was not possible to measure in each case.

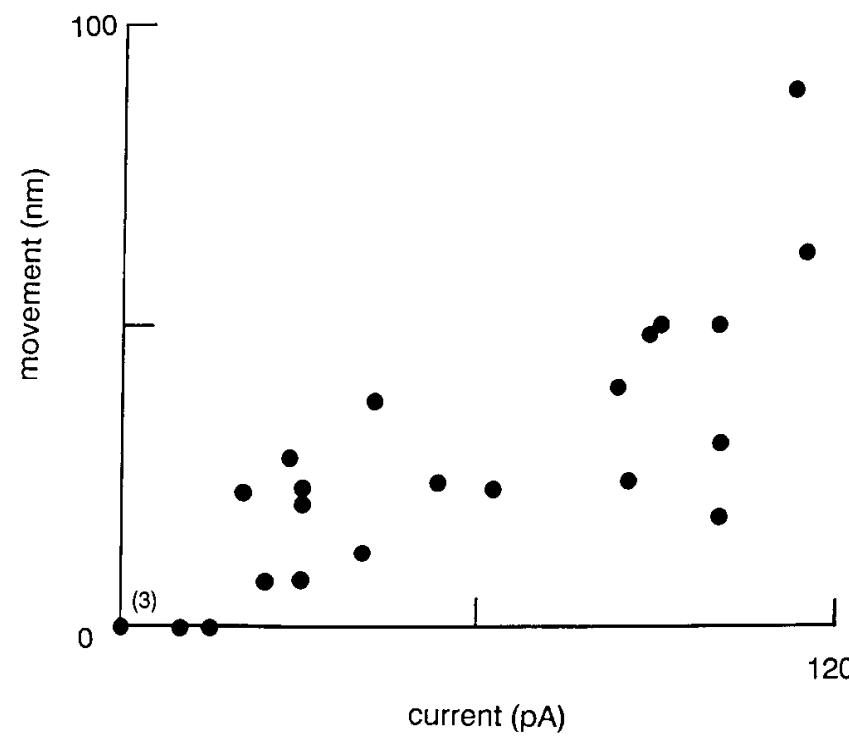

Figure 8. Amplitude of bundle movement as a function of transduction current. Bundle movement was elicited in 24 cells with depolarizing voltage steps from -80 to $+80 \mathrm{mV}$. A stimulus probe was then immediately at tached to the bundle and the transduction current measured at $-80 \mathrm{mV}$ with a saturating triangle-wave displacement. The bundle movement was averaged over the number of recorded cycles (usually about 10 ), as in Figure $7 B$, and plotted as a function of the peak-topeak transduction current. No movement was evident in three out of three cells that completely lacked transduction current; the amplitude of movement then generally increased with the transduction current amplitude.

The active bundle movements were not dependent upon the kinocilium: active responses were observed in four cells that apparently lacked kinocilia and in a fifth cell in which the kinocilium remained basally attached but was clearly dissociated from the rest of the bundle. For three of these cells the average time constants were 201 and $38 \mathrm{msec}$, and average amplitude was $32 \mathrm{~nm}$, in reasonable concordance with the values observed in cclls with intact kinocilia.

Three other experiments reinforced the connection between bundle motion and shift of the $I\left(X_{s}\right)$ curve. First, the steadystate voltage dependence of the two phenomena was examined. Figure $9, A$ and $B$, shows examples from two different cells of the active bundle motion and $I\left(X_{s}\right)$ curves recorded over a range of membrane potential. Figure $9 B$ shows bundle motion in response to four different depolarizations. Both movement of the bundle and shift of the $I\left(X_{s}\right)$ curve were larger for larger depolarizations. Average values for a number of cells were plotted as a function of voltage in Figure $9 \mathrm{C}$. The normalized data sets are nearly superimposable. Both responses were nonlinear with membrane potential: essentially no change occurred until the depolarization exceeded $-40 \mathrm{mV}$.

Second, we expect that the voltage dependence of these processes reflects the voltage-dependent entry of $\mathrm{Ca}^{2+}$ into the tips of the stcrcocilia. Reducing extracellular $\mathrm{Ca}^{2+}$ both slows adaptation and shifts the $I\left(X_{s}\right)$ curve negatively in the same way as depolarization (Assad et al., 1989; Hacohen et al., 1989). Figure $10 \mathrm{~A}$ shows an example of the negative shift of the $I\left(X_{s}\right)$ curve with low $\mathrm{Ca}^{2+}$. In addition, lowering bath $\mathrm{Ca}^{2+}$ concentration eliminates the voltage-dependent shift of the $I\left(X_{s}\right)$ curve (Assad et al., 1989). Therefore, lowering bath $\mathrm{Ca}^{2+}$ should reduce bundle motion and shift the bundle negatively as well. To lower 
A
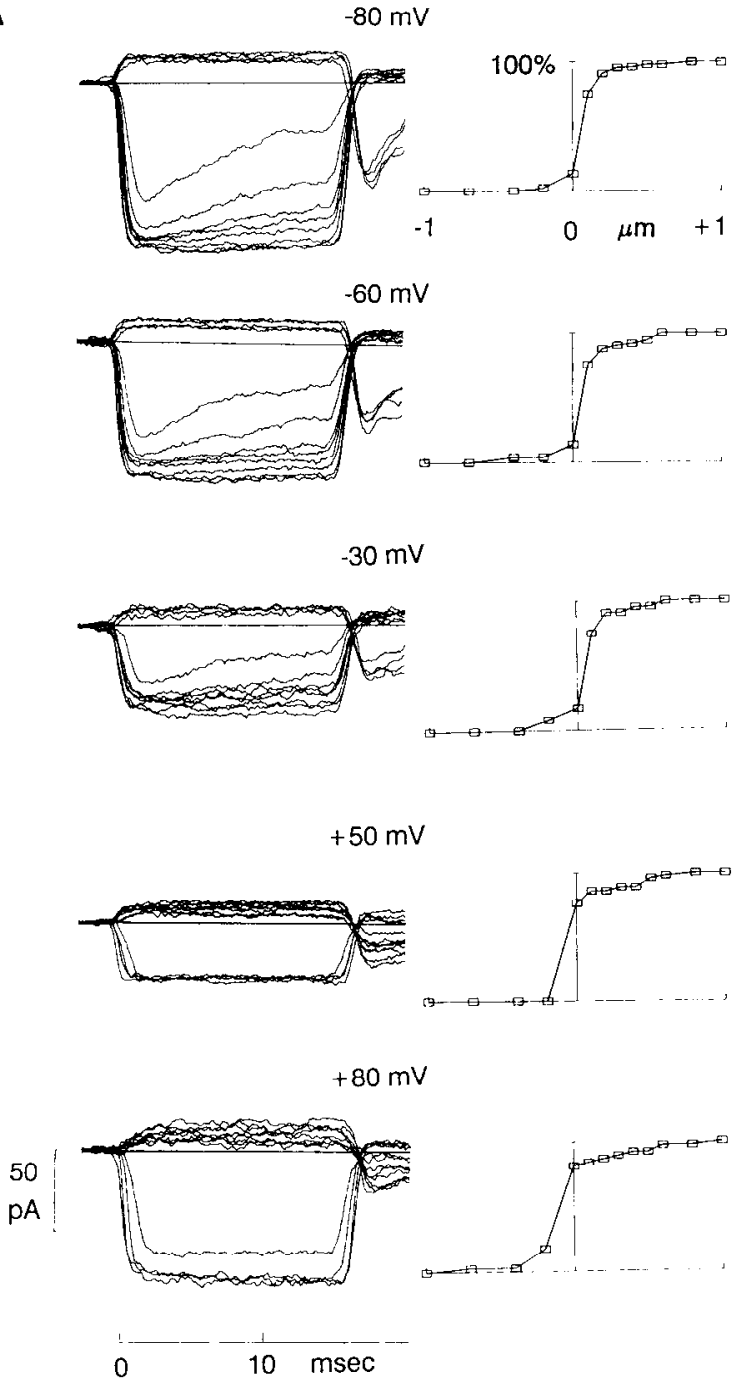

B

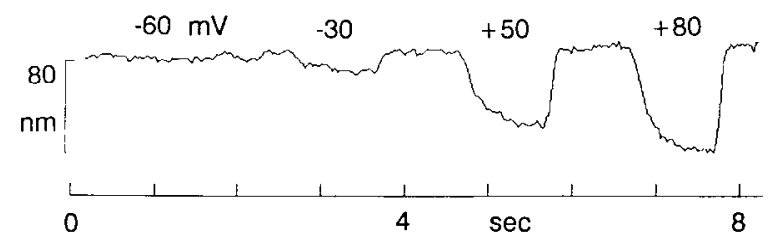

C

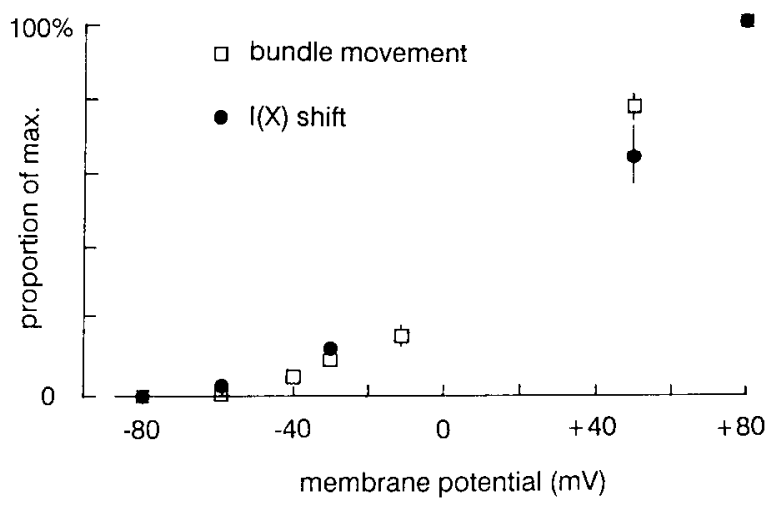

$\mathrm{Ca}^{2+}$ during recordings of active bundle motion, BAPTA was delivered to the bundle by the diffusion technique described above. In two cells, BAPTA produced a reversible inhibition of active movements; an example is shown in Figure 10B. Bulk flow of the bath fluid caused by introduction and withdrawal of the BAPTA pipette caused a transient movement of the bundle, but the intervening voltage-dependent movement was clearly reduced, and the bundle moved negatively. [As previously reported, the more usual effect of the BAPTA pipettes was cleavage of the tip links and irreversible abolition of the voltagedependent movement (Assad et al., 1991).]

Third, partially blocking concentrations of the transduction channel blocker streptomycin also slow adaptation and also bring about a negative shift of the $I\left(X_{s}\right)$ curve, presumably by antagonizing $\mathrm{Ca}^{2+}$ entry into the stereocilia (Hacohen et al., 1989). An example is shown in Figure $10 C$. It was therefore expected that the drug should at least partially obscure the voltage-dependent bundle motion by preventing $\mathrm{Ca}^{2+}$ entry at any potential. Figure $10 \mathrm{D}$ shows an example of this effect. Voltagedependent motion was clearly reduced during passage of $7 \mathrm{nA}$ of iontophoretic current, and the average bundle position was more negative during application of the drug. Reversible reduction of the voltage-dependent motion by streptomycin was observed in all four cells tested.

The $I\left(X_{s}\right)$ curve, in this model, is assumed to depend exclusively on tension in the gating spring; it should shift but not change shape when the motor position changes. Yet there is some shape change associated with shift of the curve, both in the intact sensory epithelium (Hacohen et al., 1989) and single hair cells (Assad et al., 1989; Crawford et al., 1989). We reexamined the extent of the shape change under two conditions that shift the $I\left(X_{s}\right)$ curve.

Figure 11, $A$ and $B$, shows the effect of depolarization on the $I\left(X_{s}\right)$ curve for two different cells. These illustrate the variability among cells. For both, the $I\left(X_{s}\right)$ curve at $-80 \mathrm{mV}$ was fitted with a three-state gating scheme (Corey and Hudspeth, 1983b). For the cell in Figure $11 B$, depolarization primarily shifted the

Figure 9. Steady-state voltage dependence of the $I\left(X_{s}\right)$ shift and the active bundle motion. $A, I\left(X_{s}\right)$ curves were generated by delivering 12 displacement steps at five voltages: $-80,-60,-30,+50$, and +80 $\mathrm{mV}$. Membrane potential was changed $220 \mathrm{msec}$ prior to the first displacement step. Each displacement set consisted of 12 steps of $15 \mathrm{msec}$ duration, delivered at $70 \mathrm{msec}$ intervals. Displacement amplitudes were $-1.0,-0.7,-0.4,-0.2,0.1,0.2,0.3,0.4,0.5,0.6,0.8$, and $1.0 \mu \mathrm{m}$. The current traces are shown in the left column; each trace is the average of three stimulus presentations. The corresponding $I\left(X_{s}\right)$ at each voltage is shown in the right column. Note that at +50 and $+80 \mathrm{mV}$, the $I\left(X_{s}\right)$ curves are so biased in the negative direction that nearly all of the transduction channels are open with zero displacement. Thus, negative displacements at these voltages shut off a large outward current, producing an apparent inward current. $B$, Active bundle motion elicited by a series of $1 \mathrm{sec}$ depolarizations from a holding potential of $-80 \mathrm{mV}$ to $-60,-30,+50$, and $+80 \mathrm{mV}$, delivered at 2 sec intervals. The movement trace is the average of 12 cycles of the voltage series. $C$, Average steady-state voltage dependence of the $I\left(X_{s}\right)$ shift and the active bundle motion. For cells analyzed as in $A$, the $I\left(X_{\mathrm{s}}\right)$ shift was determined at each voltage by translating the reference $I\left(X_{s}\right)$ curve obtained at -80 $\mathrm{mV}$ to obtain a best fit by eye. Because the largest shift varied among cells, the data were expressed as a percentage of the shift at $+80 \mathrm{mV}$ and averaged. Eight cells were averaged at -60 and $-30 \mathrm{mV} ; 21$ cells were averaged at +50 and $+80 \mathrm{mV}$. Active bundle movement was recorded and averaged among eycles for each cell, as in $B$, and expressed as a fraction of the movement at $+80 \mathrm{mV}$. Each movement point is the average of 12 cells. Error bars are SEM. 

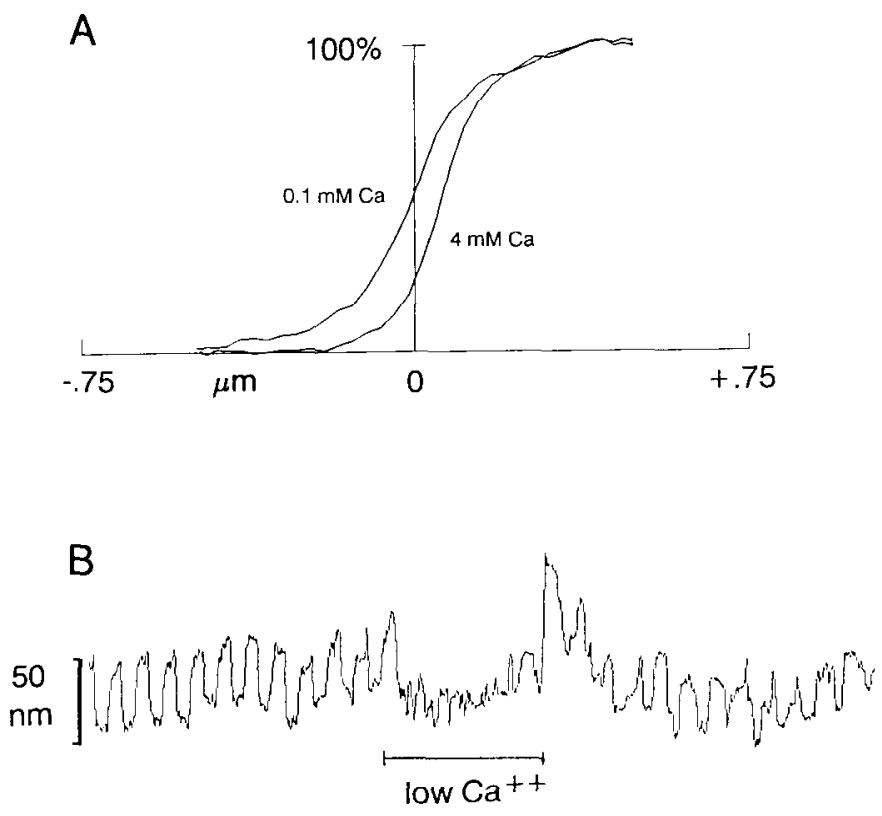

0

$20 \mathrm{sec}$
40
C

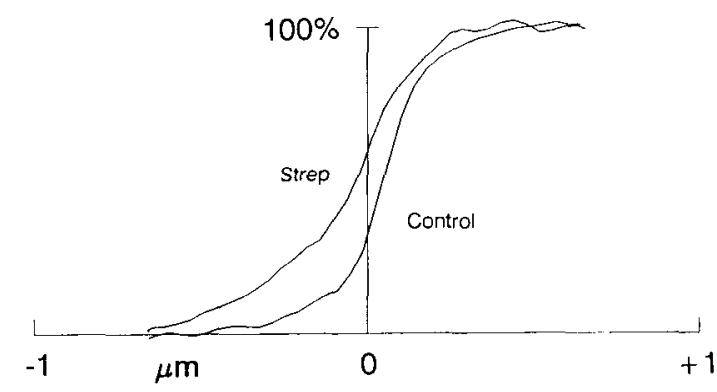

D

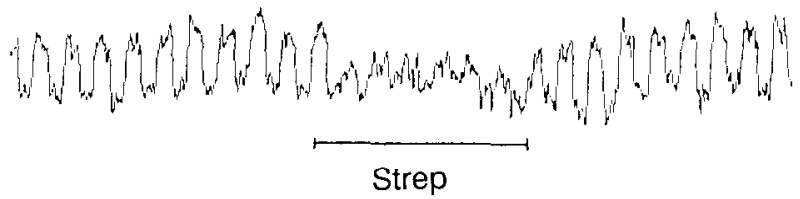

$20 \mathrm{sec}$

Figure 10. Effect of dihydrostreptomycin and reduced $\mathrm{Ca}^{2+}$ on the $I\left(X_{s}\right)$ curve and on the active bundle motion. $A$, Continuous $I\left(X_{s}\right)$ curvesgenerated by plotting the transduction current elicited by a $1 \mu \mathrm{m}$ peak-to-peak triangle wave of displacement against an optical record of the probe motion - were measured while the cell was bathed in normal $4 \mathrm{mM} \mathrm{Ca}^{2+}$ bath or during continuous pressure ejection of a solution containing 0.1 $\mathrm{mm} \mathrm{Ca}^{2+} . B$. Active bundle motion was elicited by $1 \mathrm{sec}$ depolarizations from -80 to $+80 \mathrm{mV}$, repeated every 2 sec. During the time indicated by the bar, $\mathrm{Ca}^{2+}$ concentration about the bundle was reduced by positioning a pipette filled with $20 \mathrm{~mm}$ BAPTA about $10 \mu \mathrm{m}$ from the bundle. The large bundle deflection occurring at the end of the reduced $\mathrm{Ca}^{2+}$ exposure was presumably a mechanical artifact resulting from rapid withdrawal of the BAPTA pipette. $C$, The same procedure was followed as in $A$, but $200 \mu \mathrm{M}$ dihydrostreptomycin sulfate in normal bath solution was pressure ejected onto the bundle for about $10 \mathrm{sec}$. As the drug diffused away, the current slowly recovered to full amplitude. The $I\left(X_{s}\right)$ curve labeled $S t r e p$ was measured after the current had recovered to $-70 \%$ of maximum. In both $A$ and $C$, the shift of the $I\left(X_{s}\right)$ curve was fully reversible. $D$, Active bundle motion was elicited as in $B$. An iontophoresis micropipette containing $500 \mathrm{~mm}$ dihydrostreptomycin sulfate was positioned about $5 \mu \mathrm{m}$ from the bundle. During the time indicated by the $b a r$, the drug was delivered by passage of $7 \mathrm{nA}$ of iontophoretic current. In both $D$ and $B$, the bundle was moved in the negative direction (shown as downward) by the test treatment. Different cells were used in $A-D$.

curve, with no appreciable change in shape. For the cell in Figure $11 \mathrm{~A}$, there was broadening with depolarization that was better fitted with an alternative theory (see Discussion).

We also examined the shape change of the $I\left(X_{s}\right)$ curve following displacements that cause a much larger shift. The $I\left(X_{s}\right)$ curve was measured in detail at rest and following a $0.7 \mu \mathrm{m}$, $200 \mathrm{msec}$ displacement in both the positive and negative directions (Fig. $11 C, D)$. The resting $I\left(X_{s}\right)$ was again fitted with a smooth curve corresponding to the three-state scheme. In Figure $11 C$, the fitted curve was shifted along the displacement axis to represent a change in the mechanical stimulus to the channels. For both positive and negative adapting steps, the curves clearly became broader as they shifted, but the effect was slight. In Figure $11 D$, the same data were instead fitted by the alternative theory.

\section{Discussion}

The essential feature of our model for adaptation is that the process is mediated by an adjustment of the tension in the gating springs. This viewpoint was chosen because adaptation is primarily characterized by a shift of the $I\left(X_{s}\right)$ curve along the displacement axis, without much change in shape (Fig. 11; see also Corey and Hudspeth, 1983a; Eatock et al., 1987; Assad et al., 1989; Hacohen et al., 1989), and because application of force to the bundle causes a slow relaxation with the time course of adaptation (Howard and Hudspeth, 1987). Howard and Hudspeth suggested that the transient component of the stiffness could be caused by the active movement of the tip link insertion. To their qualitative model we have added a quantitative description that allows the model to be more rigorously tested. The features that enable the quantitative model to make predictions are the extraction of slipping and tensioning rates from the $R\left(X_{s}\right)$ curve, and the interpretation of the breakpoint in the $R\left(X_{s}\right)$ curve as representing the slack point of the gating spring. The model has essentially no free parameters: all of its predictions are derived from the characteristics of the $R\left(X_{s}\right)$ curve at -80 and $+80 \mathrm{mV}$ and on the estimated spring constants of the gating and stcreocilia springs (Howard and Hudspeth, 1987). The spring constants measured by Howard and Hudspeth were calculated with the assumption that the transient component of bundle stiffness represents the gating springs; these constants help predict an independent set of behaviors described here.

The main question these experiments address is whether a single process can account for features associated with adaptation [the displacement-, voltage-, and calcium-dependent shift of the $I\left(X_{s}\right)$ curve], as well as mechanical behavior of the hair cell (the voltage- and calcium-dependent movement of the bundle). If a free-standing bundle is moved by the same mechanism as underlies adaptation, it is difficult to avoid the notion of an active, force-producing "motor" as the basis of adaptation. 
A

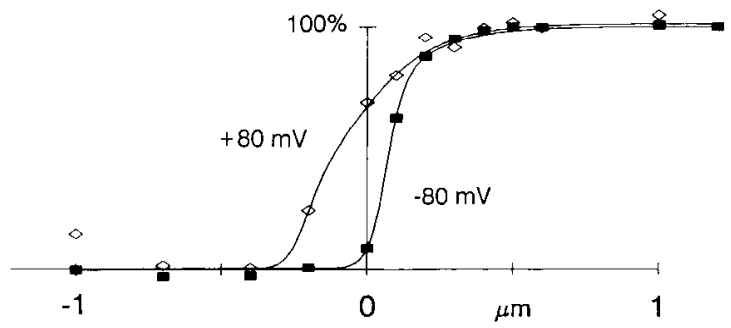

B
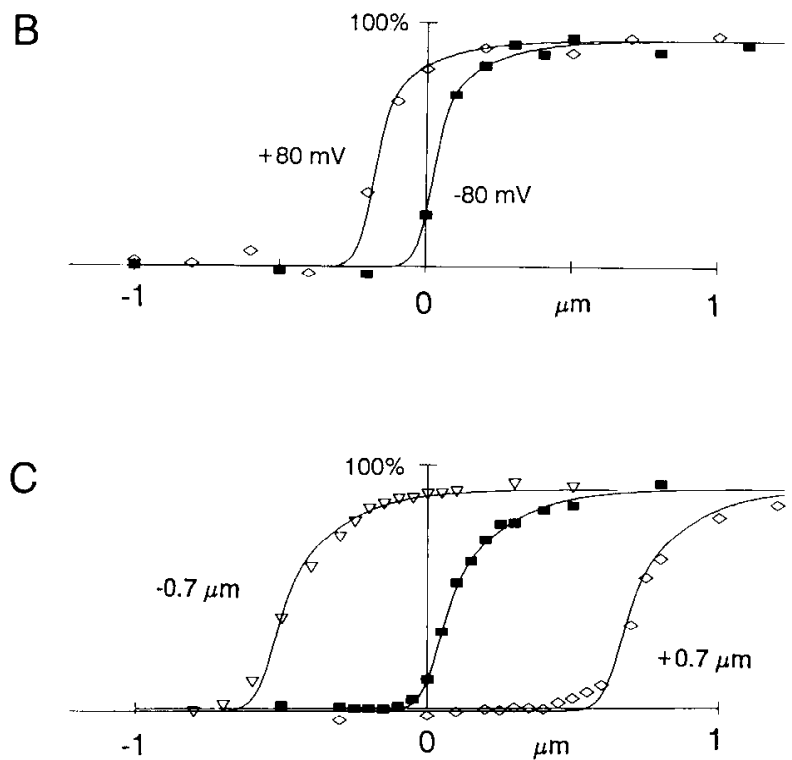

D

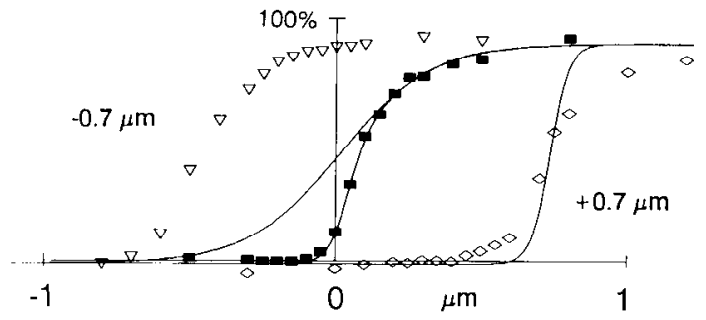

Figure 11. Modeling adaptation as a shift of the $I\left(X_{s}\right)$ curve or as a change in closed-state energy. $I\left(X_{s}\right)$ curves in $A$ and $B$ were generated at both -80 and $+80 \mathrm{mV}$ by a procedure similar to that described in Figure $9 \mathrm{~A}: 12$ displacements of $15 \mathrm{msec}$ duration were delivered at 70 msec intervals while membrane potential was alternated between -80 and $+80 \mathrm{mV}$. $A$. The $I\left(X_{s}\right)$ curve at $80 \mathrm{mV}$ (solid symbols) was fitted according to the scheme of Equation 10 with $G_{1}=12.5 \times 10^{-21} \mathrm{~J}, Z_{1}$ $=119 \mathrm{fN}, G_{2}=-2.7 \times 10^{-21} \mathrm{~J}$, and $Z_{2}=28 \mathrm{fN}$. The $I\left(X_{s}\right)$ curve at $+80 \mathrm{mV}$ (open symbols) was fitted with the same curve, except that the $G_{1}$ parameter was changed to $-24.2 \times 10^{-21} \mathrm{~J}$, where $G_{1}$ is the energy difference between the second closed state and the first closed state. $B$, The $I\left(X_{s}\right)$ curve at $-80 \mathrm{mV}$ (solid symbols) was fitted according to Equation 10 with $G_{1}=6.8 \times 10^{-21} \mathrm{~J}, Z_{1}=134 \mathrm{fN}, G_{2}=-2.7 \times 10^{-21}$ $\mathrm{J}$, and $Z_{2}=28 \mathrm{fN}$. The $I\left(X_{\mathrm{s}}\right)$ curve at $+80 \mathrm{mV}$ (open symbols) was fitted with an identically shaped theoretical curve, shifted negatively by $193 \mathrm{~nm}$. In $C$ and $D$, membrane potential was held at $-80 \mathrm{mV}$ and the $I\left(X_{s}\right)$ curve mapped following a 200 msec displacement of $+0.7 \mu \mathrm{m}$ (diamonds) or $-0.7 \mu \mathrm{m}$ (inverted triangles). In each trace, a single 20 msec test displacement was superimposed on the maintained displacement; the amplitude was varied among 16 test-displacement amplitudes. Stimulus presentations were repeated at $600 \mathrm{msec}$ intervals. The resting $I\left(X_{s}\right)$ curve (solid symbols) - measured before the $200 \mathrm{msec}$ displacement - was fitted according to Equation 10 with $G_{1}=6.1 \times 10^{-21}$ $\mathrm{J}, Z_{1}=109 \mathrm{fN}, G_{2}=0.7 \times 10^{-21} \mathrm{~J}$, and $Z_{2}=27 \mathrm{fN}$. $C$, The $I\left(X_{s}\right)$ measured after the $+0.7 \mu \mathrm{m}$ displacement was fitted by shifting the theoretical resting $I\left(X_{s}\right)$ curve by $621 \mathrm{~nm}$ in positive direction, without

\section{Tests of the model}

First, the model predicts a steady-state tension in the gating spring, which sets the resting open probability of transduction channels and the position of the $I\left(X_{\mathrm{s}}\right)$ curve. With the measured adaptation rates at -80 and $+80 \mathrm{mV}$, the change in the steadystate position of the $I\left(X_{\mathrm{s}}\right)$ curve with depolarization was predicted to be $-124 \mathrm{~nm}$. The measured shift was $139 \pm 40 \mathrm{~nm}$.

Second, the time course of the $I\left(X_{s}\right)$ curve shift was predicted to be asymmetric, with time constants of $65 \mathrm{msec}$ on depolarization and $12 \mathrm{msec}$ on repolarization. The measured time course was similar, with the slower time constant on depolarization of $61 \mathrm{msec}$ [from the $I\left(X_{s}\right)$ shift] or $72 \mathrm{msec}$ (calculated from the shift current), and a time constant on repolarization of $9 \mathrm{msec}$ [the $I\left(X_{s}\right)$ shift] or $14 \mathrm{msec}$ (the shift current).

A departure from the predicted behavior was the biphasic nature of the $I\left(X_{s}\right)$ shift with depolarization. Measured either way, this shift had a fast phase with a 4-7 msec time constant, in addition to the predicted slower phase. The discrepancy was not glaring, but may suggest certain modifications to the basic model. It was assumed in the theory that the parameters of the $R\left(X_{s}\right)$ curve-the slope $S$ and offset $C$-are instantaneous functions of voltage. While this assumption allows for a clean analytical solution (Eq. 2), it may not represent the true physical situation. On repolarization of the membrane potential from +80 to $-80 \mathrm{mV}$, the $\mathrm{Ca}^{2+}$ concentration is expected to rise rapidly in the tips of the stereocilia as it enters through transduction channels. We found that repolarization facilitates the slipping process nearly instantaneously, and concluded that the site of action for $\mathrm{Ca}^{2+}$ is near the tips of the stereocilia (Assad et al., 1989). Dissipation of $\mathrm{Ca}^{2+}$ from its site following the block of entry by depolarization might take longer. If $\mathrm{Ca}^{2+}$ is cleared from the stereocilia by diffusion, its concentration would decline along the entire length of the stereocilium, but would remain at all times highest at the tip. Slow dissociation of $\mathrm{Ca}^{2+}$ from a high-affinity receptor might also add a delay. It is possible, finally, that calcium's effect on tensioning may be at a more distant site than its effect on slipping. Using an iterative computer simulation, we found that the fast component of the $I\left(X_{s}\right)$ shift upon depolarization could be duplicated by assuming that slipping is an instantaneous function of voltage, but that tensioning approaches its new rate with a time constant of $6 \mathrm{msec}$. While other such modifications to the theory might fit as well, this illustrates that a simple and plausible effect could account for the difference.

A third prediction of the theory is that the motor generates a steady-state tension in the gating spring that pulls the stereocilia in the negative direction. If it were possible to cut the gating springs, the bundle should relax forward to the intrinsic rest position of the stereocilia spring, by an amount equal to $(\mathrm{C} /$ $S)\left(K_{g} / K_{s}\right)$. From the $R\left(X_{s}\right)$ curve at $-80 \mathrm{mV}, C / S=194 \mathrm{~nm}$; with the values of $K_{g}(0.43 \mathrm{mN} / \mathrm{m})$ and $K_{s}(0.53 \mathrm{mN} / \mathrm{m})$ from Howard and Hudspeth $(1987,1988)$, this predicts a movement of $155 \mathrm{~nm}$. We have found that reduction of extracellular $\mathrm{Ca}^{2+}$

changing the shape of the curve. The $I\left(X_{s}\right)$ measured after the $-0.7 \mu \mathrm{m}$ displacement was similarly fitted by shifting the theoretical curve by $-563 \mathrm{~nm} . D$, The same data as in $C$ were fitted by changing only the parameter $G_{1}$ from the theoretical fit of the resting $I\left(X_{s}\right)$ curve. For the $+0.7 \mu \mathrm{m}$ displacement, $G_{1}$ was changed from 6.1 to $100 \times 10^{-21} \mathrm{~J}$; for the $-0.7 \mu \mathrm{m}$ displacement, $G_{1}$ was reduced from 6.1 to $-70 \times 10^{-21} \mathrm{~J}$. 
with BAPTA cuts the tip links, and causes a forward bundle movement of $133 \pm 70 \mathrm{~nm}$ (Assad et al., 1991).

Fourth, since the predicted steady-state tension is also voltage dependent, a freestanding bundle should move negatively by 99 $\mathrm{nm}$ with depolarization to $+80 \mathrm{mV}$. Observed movement was variable in amplitude, ranging from 0 to $106 \mathrm{~nm}$, but averaged about $50 \mathrm{~nm}$ and was always negative in direction.

Finally, the predicted time course of the bundle movement was also asymmetric, with time constants of $117 \mathrm{msec}$ on depolarization and $22 \mathrm{msec}$ on repolarization. The movement measured by video was asymmetric but somewhat slower: the (single) time constant on depolarization was $193 \pm 82 \mathrm{msec}$ and that on repolarization was $56 \pm 24 \mathrm{msec}$. As mentioned in Materials and Methods, the intrinsic lag of the video measuring system can account for the slowed response with repolarization, but not that with depolarization. The movement may also have been slowed by damping on the bundle. Howard and Hudspeth (1987) observed that bundles in the intact epithelium followed the movement of a force probe with minimal delay, indicating that the bundles were only lightly damped. Ising nearly the same preparation, Denk et al. (1989) showed that the powerspectral density of the bundle's Brownian motion rolled off between 200 and $800 \mathrm{~Hz}$, suggesting that the bundle should follow an applied force in less than $1 \mathrm{msec}$. However, with the dissociated hair cells used in our experiments the bundles lie within a few micrometers of the bottom of the recording chamber and may thus be subject to greater viscous or frictional forccs. In that regard, Crawford et al. (1989) observed a much more sluggish response of the hair bundle following a force step in dissociated turtle cochlear hair cells. If damping is in fact responsible for the discrepancy, the damping coefficient must be $50-$ $60 \mu \mathrm{N} \mathrm{sec} \mathrm{m}^{-1}$ (Eq. 8). Further experiments are needed to determine if this is a reasonable number.

A variety of active movements have been reported in hair cells. Particularly well studied is the voltage-dependent elongation of the cell body observed in outer hair cells from mammalian cochlea (Brownell et al., 1985; Ashmore, 1987; Dallos et al., 1991). Additionally, there have been reports of active tilting of the cuticular plate of outer hair cells in response to alternating external electric fields (Zenner et al., 1988). Both phenomena are apparently unrelated to the active bundle motion reported here: in our cells digital image subtraction indicated that the movement was confined to the bundle alone, and we could detect no movement in the cell body of more than a few nanometers in amplitude (Fig. $6 B$ ). Other active movements in hair cells have been observed to involve only the bundle, but are faster or of different polarity than the movements reported here (Crawford and Fettiplace, 1985; Howard and Hudspeth, 1988; Denk, 1989; Jaramillo et al., 1990). Our results are apparently also distinct from the electrically induced bundle movements in hair cells of the intact eel ampulla (Rusch and Thurm, 1990), which have the same polarity and a comparable amplitude as those reported here, but differ in that kinocilia also move, even if dissociated from the stereocilia. In addition, the ampullary hair cell movements did not display an asymmetry in the time course of their negative and positive components, and were not blocked-either reversibly or irreversibly - by lowering the $\mathrm{Ca}^{2+}$ concentration about the bundles.

Further tests linking adaptation with bundle movement involve the voltage, calcium, and aminoglycoside dependence. The voltage-dependent change in resting tension should produce proportional movement of freestanding bundles and shifts in the $I\left(X_{s}\right)$ curve. Over a range of voltages, these independent measures agreed very well, with both exhibiting voltage sensitivity above $-40 \mathrm{mV}$ (Fig. 9).

The voltage dependence of adaptation is thought to be a consequence of calcium entry, because it is blocked by removal of extracellular calcium (Assad et al., 1989; Crawford et al., 1989). Similarly, removing calcium shifts the $I\left(X_{s}\right)$ negatively (Fig. $10 \mathcal{A})$ and blocks a further negative shift of the $I\left(X_{s}\right)$ curve with depolarization (Assad et al., 1989). We found that reducing calcium also moves the bundle negatively and blocks the negative movement of the bundle with depolarization (Fig. 10B). This effect is reversible in some experiments, presumably those in which the calcium reduction was not sufficient to cut the tip links.

Aminoglycoside antibiotics, which plug the pore of the transduction channels (Kroese et al., 1989), also are expected to block calcium entry. In our cxpcriments, dihydrostreptomycin induced a negative shift of the $I\left(X_{s}\right)$ curve and blocked the voltagedependent movement. In a related experiment (Denk, 1989), streptomycin iontophoresis at the resting potential produced a slow negative bundle movement much like the depolarizationinduced movement reported here.

In all these tests, the movement of the $I\left(X_{s}\right)$ curve and the movement of the hair bundle were reasonably well predicted by a theory based on an active adaptation motor. Although the correspondence was not perfect, amplitudes and time constants were within a factor of 2 of predicted values.

\section{Limitations to the model}

The model outlined in Theory does not predict all aspects of adaptation. One such aspect is that adaptation is not always complete. For displacements greater than about $200 \mathrm{~nm}$, the size of the adaptative shift of the $I\left(X_{s}\right)$ curve at steady state is usually smaller than the displacement that elicits it; thus, the open probability of the channels does not return completely to its resting level (Eatock et al., 1987; Corey et al., 1987; Hacohen et al., 1989). In Figure 11 , for instance, the $I\left(X_{s}\right)$ curve shifted by $80 \%$ or $88 \%$ of the displacement, for negative or positive steps. The exact mechanism remains unclear, and may imply a limited range for the adaptation motor. However, the model's basic features would not be changed by incorporating the incompleteness for adaptation, and it would not affect the predictions for most of our data, which involve displacements of less than $200 \mathrm{~nm}$.

A second such aspect is that the $I\left(X_{s}\right)$ curve often becomes slightly broader with adaptation. Maintained bundle displacements cause the $I\left(X_{s}\right)$ curve to change shape somewhat as well as shift, both in bullfrog saccular hair cells (Assad et al., 1989) and in turtle cochlear hair cells, where the effect is apparently more pronounced (Crawford et al., 1989, 1991). One possibility is that the transduction elements are discrete units, with each motor having a distinct set point (Assad et al., 1989). Individual units may adapt with different completeness during a maintained displacement, causing the macroscopic $I\left(X_{4}\right)$ curve to smear. For instance, each gating spring might have a distinct "track" along which its insertion can slide, with the unobstructed length of the track varying among stereocilia. There is also broadening of the curve associated with depolarization, and with reduced intra- or extracellular $\mathrm{Ca}^{2+}$. These treatments shift the resting $I\left(X_{s}\right)$ curve to the left, which is a consequence, in our 
model, of increasing the $C / S$ ratio. If a larger ratio also means more scatter in the ratio among individual motors of a bundle, then the scatter in individual set points would smear the macroscopic $I\left(X_{s}\right)$ curve (Assad et al., 1989). An alternative theory is discussed below.

A third concern is why the limiting tensioning rate, $C$, was slower at +80 than at $-80 \mathrm{mV}$. This was seen in the $R\left(X_{s}\right)$ curves for large negative displacements (Fig. 3). The simple model would predict that negative displacements would close all channels and reduce intracellular $\mathrm{Ca}^{2+}$ to the same extent, at either membrane potential, and that the rates should be the same. It may be that the time required to clear $\mathrm{Ca}^{2+}$ from its site of action accounts for the difference. To generate an $R\left(X_{s}\right)$ curve at $+80 \mathrm{mV}$, the cells were depolarized $200 \mathrm{msec}$ prior to delivering the negative bundle displacement, whereas at -80 $\mathrm{mV}$ there was $\mathrm{Ca}^{2+}$ entry until the moment the bundle was displaced. The initial rate of adaptation was measured during the first $20 \mathrm{msec}$; therefore, the negative rate at $-80 \mathrm{mV}$ may have been elevated, if the $\mathrm{Ca}^{2+}$ concentration at the "adaptation site" had not decreased to its equilibrium value. Alternatively, it may be that even with the transduction channels closed, the steady-state $\mathrm{Ca}^{2+}$ concentration within stereocilia is different at

-80 and $+80 \mathrm{mV}$. For example, if there are mechanisms for active extrusion of $\mathrm{Ca}^{2+}$ from the stereocilia, they may be enhanced by depolarization. Lastly, it is still possible that the motor or some other element in the adaptation machinery has a transmembrane domain that can respond directly to membrane potential to affect the tensioning rate.

\section{Alternative models for adaptation}

It has recently been proposed that adaptation does not involve a change in the tension stimulus to the channels per se, but rather how the channels respond to a constant tension. In experiments on turtle cochlear hair cells, Crawford et al. (1989, $1991)$ noted that the $I\left(X_{s}\right)$ curve changes its shape as it shifts along the displacement axis. The shape of the $I\left(X_{s}\right)$ curve can be described by a gating scheme that includes two closed states and a single open state for the transduction channels (Corey and Hudspeth, 1983b). The current is proportional to the probability of the channel being in the open state, which is given by

$$
P_{\text {open }}=\left\{1+\exp \left[\frac{G_{2}-Z_{2} X_{s}}{k T}\right]\left[1+\exp \left(\frac{G_{1}-Z_{1} X_{s}}{k T}\right)\right]\right\}^{\cdots},
$$

where $X_{s}$ is the displacement of the bundle; $G_{1}$ and $G_{2}$, the zerodisplacement energy differences for the two transitions; and $Z_{1}$ and $Z_{2}$, the displacement sensitivities of the energy differences (Corey and Hudspeth, 1983b). Typically, the first transition is significantly more sensitive $\left(Z_{1}>Z_{2}\right)$. According to Equation 10 , a pure shift of the $I\left(X_{s}\right)$ curve-with no concomitant shape change-corresponds to an offset in the value of $X_{s}$, as would be caused by a change in the motor position. (In principle, a pure shift could also be caused by a change in both $G$ terms in proportion to their respective $Z$ terms.) A change in either $G$ term alone will cause the $I\left(X_{s}\right)$ curve to shift, but will alter its shape as well.

Crawford et al. (1989, 1991) proposed that calcium acting at the intracellular face of the channel could stabilize the first closed state, and that changing the $G_{1}$ parameter alone could account for the response of the $I\left(X_{s}\right)$ curve to maintained displacements, depolarization, or reduced bath $\mathrm{Ca}^{2+}$ concentration. Implicit in this interpretation is a rejection of the hypothesis that adaptation acts by adjusting the tension stimulus to the channels.

We tested whether their scheme could account for the voltagedependent shift in all cells. Figure $11, A$ and $B$, shows the steadystate $I\left(X_{s}\right)$ curve plotted at both -80 and $+80 \mathrm{mV}$ for two cells. In both cases, the $I\left(X_{\mathrm{s}}\right)$ at $-80 \mathrm{mV}$ was fitted with a smooth curve according to the three-state scheme of Equation 10. For the cell in Figure $11 \mathrm{~A}$, the $I\left(X_{s}\right)$ at $+80 \mathrm{mV}$ was reasonably well fitted by changing only the value of $G_{1}$. In contrast, the cell in Figure $11 B$ could not be so simply described: the curve at +80 $\mathrm{mV}$ was clearly fitted better by shifting the $I\left(X_{s}\right)$ curve obtained at $-80 \mathrm{mV}$. In general, a variety of $I\left(X_{s}\right)$ responses were observed with depolarization; most were not perfectly described by either a simple shift or an adjustment of the $G_{1}$ parameter alone. However, the shift with depolarization was generally small, making it difficult to distinguish between the two models.

Fitting the $I\left(X_{s}\right)$ curve following displacements offers a more stringent test. Figure $11, C$ and $D$, shows two fits to the same data. In Figure $11 C$ the resting curve was shifted to represent a change in motor position; it matches the adapted curves reasonably well. In Figure $11 D$ the energy between closed states $\left(G_{1}\right)$ was adjusted to provide the best fit. The fit was extremely poor, particularly for the $I\left(X_{s}\right)$ curve following the $-0.7 \mu \mathrm{m}$ maintained displacement. The same discrepancy was seen in another cell tested with this protocol. Thus, for bullfrog saccular hair cells, changing $G_{1}$ alone does not provide an adequate general description of the $I\left(X_{s}\right)$ curve following adaptation. While the $I\left(X_{s}\right)$ curve clearly changes shape in response to adaptation, the most parsimonious explanation is that the effect is secondary to a shift of the $I\left(X_{s}\right)$ curve.

Moreover, if intracellular calcium stabilizes the closed state, the channel closure-acting through the gating springs-should pull the bundle in the negative direction. Channel opening caused by depolarization should allow a positive relaxation. In these experiments, depolarization caused a negative movement instead.

\section{Further tests of the model}

The model presented here makes further predictions that could be tested. First, the model would predict that the movement following a positive force step would be slowed at depolarized membrane potentials, where the slipping rate is reduced. This hypothesis was directly tested by Crawford et al. (1989) in dissociated turtle hair cells. In at least one cell no difference in stiffness was observed between hyperpolarized and depolarized potentials. In this experiment, adaptation of the simultaneously recorded transduction current was unusually slow, as noted by the authors, and the movement of the stimulus probe suggested an additional viscous drag of unknown origin. The result could indicate that adaptation in turtle operates by a different mechanism, but clearly bears repetition in frog hair cells.

A second prediction concerns the slack point of the gating spring. The rate of adaptation became more or less independent of displacement for negative steps, suggesting that the gating spring could become slack. If the gating spring cannot exert force when compressed, the adaptation model predicts that the $I\left(X_{s}\right)$ curve should shift at a constant rate, $C$, following a negative bundle displacement, and then change to an exponential time course when the gating spring "reengages." The amount of time climbing at the constant rate should increase linearly with the size of the negative displacement, as larger displacements would require more climbing before the gating springs reengage. This 
question could be addressed by measuring the bundle position following a force step in the negative direction. The bundle should remain at a constant position as long as the gating spring is slack, and then suddenly begin to move more negatively with an exponential time course when the gating spring becomes tight.

\section{Relation to the tip links model of transduction}

The model, as presented, makes no assumptions about the location or structural basis of the adaptation process. Parameters are defined in relation to lateral displacement of the tips of the bundle. In the tip links model for transduction (Pickles et al., 1984), the gating spring corresponds to the individual tip links between stereocilia. In their model of adaptation, Howard and Hudspeth (1987) speculate that adaptation represents the movement of the upper insertion point of the tip links. The localization of the transduction channels to the tips of the stereocilia (Hudspeth, 1982; Huang and Corey, 1990; Jaramillo and Hudspeth, 1991; cf. Ohmori, 1988), and the rapid action of $\mathrm{Ca}^{2+}$ entry on the adaptation (Assad et al., 1989) also suggest that the adaptation mechanism is at the tips of the stereocilia. The observation that bundle movement is roughly proportional to the size of the transduction current (Fig. 8) is consistent with a number of transduction motors summing to produce the wholecell behavior. Finally, preliminary morphological observations (Shepherd et al., 1991) are consistent with movement of the tip link attachment as the mechanical basis of adaptation.

If this model is true, the distances, rates, and spring constants in our model should be converted to take into account the geometry of the tip links (see Howard and Hudspeth, 1988; Hudspeth, 1992). All of the distances and rates are multiplied by the geometry factor $\gamma$ of $0.12-0.14$ to give values relative to individual tip links (indicated by lowercase variables). For instance, resting stretch of the tip links, $x_{g}=\gamma X_{z}$, would be 23 $\mathrm{nm}$, and the climbing rate along the side of the stereocilia, $c=$ $\gamma C$. would be $1.9 \mu \mathrm{m} / \mathrm{sec}$ at $-80 \mathrm{mV}$. Individual spring constants depend on the geometry and number of stereocilia. The single stereocilium stiffness is $k_{s}=K_{s} / N$ measured laterally at the height of the kinocilium, or $k_{\mathrm{s}}=K_{s} / N \gamma^{2}$ as seen by an individual motor. An individual tip link would have stiffness seen by the motor of $k_{g}=K_{g} / N \gamma^{2}$, or about $600 \mu \mathrm{N} / \mathrm{m}$. Resting tension in the tip link, $t_{k}=k_{x} x_{k}$, is then about $14 \mathrm{pN}$.

The model can also be used to infer the tension on a channel that is just sufficient to open it half the time. For 13 cells, $I\left(X_{s}\right)$ curves were measured and fitted with a theoretical curve according to the scheme of Equation 10. The average bundle displacement sufficient to open $50 \%$ of the channels was $73 \pm 33$ $\mathrm{nm}$ from rest. The apparent slack position of the gating springs is $194 \mathrm{~nm}$ negative to the normal resting position of the bundle, so total stretch for $50 \%$ open is $267 \mathrm{~nm}$ relative to lateral deflection of the bundle, or $32 \mathrm{~nm}$ along a tip link. The tension to open a channel half the time is then $19 \mathrm{pN}$. Conventional molecular motors exert forces closer to 1-2 pN (Huxley and Simmons, 1971); if such a molecule powers adaptation, it may be that the motor acting on each tip link is a complex of a dozen or so molecules.

For the same 13 cells, the average open probability at the slack point of $-194 \mathrm{~nm}$ can be calculated according to Equation 10: it is about $0.02 \%$. This accords with ensemble variance measurements of the transduction current, which suggest that the channels are closed virtually $100 \%$ of the time with negative saturating displacements (Holton and Hudspeth, 1986).

\section{Nature of the adaptation motor}

What is the chemical nature of the motor? Candidate mechanisms must reconcile three characteristics of the $R(X)$ curve: (1) the slipping rate increases linearly for positive displacements, (2) the climbing rate is constant for negative displacements greater than $C / S$, and (3) the slipping rate decreases more than the climbing rate when $\mathrm{Ca}^{2+}$ entry is reduced by depolarization.

If there is an adaptation motor, which does mechanical work to move the bundle against the spring constant of the stereocilia, then it must consume energy. Several families of motor proteins that hydrolyze ATP have been described; these are naturally candidates. Yet we might first consider "passive" motors that have an indirect energy source. For instance, the passive mechanical properties of a cytoskeletal element could be modulated by $\mathrm{Ca}^{2+}$ entry into the stereocilia. This could in effect power an active mechanism: if the stiffness of the cytoskeletal element increased as $\mathrm{Ca}^{2+}$ was cleared from the stereocilia, a given stretch of the element would store more potential energy-energy that could be made available to do work on the gating springs. The metabolic cost for the process would thus be borne indirectly by the pumps that maintain the $\mathrm{Ca}^{2+}$ gradient. There is precedence for modulation of cytoskeletal compliance by enzymatic mechanisms (Mooseker et al., 1980) or even directly by ATP (Janmey et al., 1990). Suppose that the insertion point of each gating spring is free to move in a viscous fashion, and is attached to a long elastic element. If this element is much longer than the displacement of the gating springs, the force exerted by it would remain essentially unchanged throughout the sensitive range of a cell. If the gating springs are slack, they would be retensioned at a constant velocity equal to the tension in the elastic element divided by the damping coefficient of the attachment point. One could imagine that low $\mathrm{Ca}^{2+}$ stiffens this elastic element, leading to more resting tension. However, a stiffer spring would also increase the tensioning rate. Instead, this rate was decreased at depolarized potentials that block $\mathrm{Ca}^{2+}$ entry (Fig. 3). To remain viable, the model must also incorporate a compensatory $\mathrm{Ca}^{2+}$-dependent viscosity, which seems excessively ad hoc.

The cores of the stereocilia are a stiff scaffolding of actin filaments cross-linked by fimbrin. This led to the suggestion that the motor might be a myosin-like protein, which could climb along the stereocilium if unloaded, or slip if excessivcly loaded (Howard and Hudspeth, 1987; Hacohen et al., 1989). Demembranated cores of stereocilia do, in fact, support a myosin-hased motility: beads coated with chicken muscle myosin move upward along isolated cores at 1-2 $\mu \mathrm{m} / \mathrm{sec}$ (Shepherd et al., 1990). Moreover, adaptation in bullfrog hair cells is blocked by a nonhydrolyzable analog of ATP in the cytoplasm (Gillespie and Hudspeth, 1992).

How well could such a motor accommodate the empirical propertics of adaptation? In a simple model (Toyoshima et al., 1990), a motor makes one step of distance $D_{m}$ for each cycle of ATP hydrolysis. If the average time for one cycle is $t_{c}$, then the tensioning rate with no load on the motor is just $D_{m} / t_{i}$. When there is tension on the motor, it may slip during the part of each cycle when it is unbound from its substrate. During the unbound time $t_{u}$, the rate of slipping is determined by the force in the gating spring $T_{g}$ and the coefficient of viscous damping $B$ as the motor slips; the slipping rate is $T_{k} / B$. However, the motor cannot slip when bound, so the overall slipping rate depends on the proportion of time the motor can slip; the rate is then $\left(T_{x} / B\right)\left(t_{u} /\right.$ 
$t_{c}$ ). In the adaptation model, the tension in the gating spring $T_{g}$ $=K_{g} X_{g}$, so the slipping rate is $\left(K_{g} / B\right)\left(t_{u} / t_{c}\right) X_{g}$.

These two rates are equivalent to the variables describing slipping and tensioning above, if

$$
C=D_{m} / t_{c}
$$

and

$$
S=\left(K_{g} / B\right)\left(t_{u} / t_{c}\right) .
$$

How would the observed effects of depolarization on $S$ and $C$ be interpreted in terms of these microscopic variables? Depolarization from $-80 \mathrm{mV}$ to $+80 \mathrm{mV}$ reduces $C$ by a factor of 3 . Assuming the step size does not change, the cycle time must be lengthened by 3 times. Depolarization reduces $S$ by about 5 times; assuming $\left(K_{g} / B\right)$ is constant, the unbound time must decrease by a factor of $5 / 3$. The bound time must then increase by more than 3 times. It does not seem unreasonable that a decrease in $\mathrm{Ca}^{2+}$ would slow the off rate and speed the on rate for a motor binding to a substrate.

An interesting feature of this model is that the steady-state stretch of the gating spring can be calculated in these terms. When $C=S X_{g}$, then $X_{g}=D_{m}\left(B / K_{g}\right)\left(1 / t_{u}\right)$. The term $B / K_{g}$ is the time constant for slipping when unbound, so $X_{g}=D_{m} \tau_{\text {sip }} / t_{u}$.

The preceding scheme is obviously somewhat simplified; for example, the effect of gating spring tension on the rates of binding and unbinding has not been taken into account, as has been done in modeling crossbridge dynamics in skeletal muscle (Huxley, 1957). It also considers just a single motor molecule, while the force calculations raise the possibility that the motor complex might include a dozen or more molecules. Nonetheless, it illustrates in principle how a mechanoenzyme could be modulated in a simple fashion by $\mathrm{Ca}^{2+}$ to recapitulate the shape of the $R\left(X_{s}\right)$ curve at different membrane potentials. Moreover, this type of analysis provides a framework from which more quantitative predictions concerning the microscopic behavior of the motor could be made.

\section{References}

Ashmore JF (1987) A fast motile response in guinea-pig outer hair cells: the cellular basis of the cochlear amplifier. J Physiol (Lond) 388: 323-347.

Assad JA (1991) Sensory adaptation in vertebrate hair cells. PhD thesis, Harvard University.

Assad JA, Hacohen N, Corey DP (1989) Voltage dependence of adaptation and active bundle movement in bullfrog saccular hair cells. Proc Natl Acad Sci USA 86:2918-2922.

Assad JA, Shepherd GMG, Corey DP (1991) Tip-link integrity and mechanical transduction in vertebrate hair cells. Neuron 7:985-994.

Barres BA, Koroshetz WJ, Chun LLY, Corey DP (1990) Ion channel expression by white matter glia: the type-1 astrocyte. Neuron 5:527544.

Brownell WE, Bader CR, Bertrand D, de Ribaupierre Y (1985) Evoked mechanical responses of isolated cochlear outer hair cells. Science 227:194-196.

Corey DP, Hudspeth AJ (1979) Ionic basis of the receptor potential in a vertebrate hair cell. Nature 281:675-677.

Corey DP, Hudspeth AJ (1980) Mechanical stimulation and micromanipulation with piezoelectric bimorph elements. J Neurosci Methods 3:183-202.

Corey DP, Hudspeth AJ (1983a) Analysis of the microphonic potential of the bullfrog's sacculus. J Neurosci 3:942-961.

Corey DP, Hudspeth AJ (1983b) Kinetics of the receptor current in bullfrog saccular hair cells. J Neurosci 3:962-976.

Corey DP, Smith WJ, Barres BA, Koroshetz WJ (1987) Calmodulin inhibitors block adaptation in vestibular hair cells. Soc Neurosci Abstr 13:538a.
Corey DP, Hacohen N, Huang PL, Assad JA (1989) Hair cell stereocilia bend at their bases and touch at their tips. Soc Neurosci Abstr 15: $208 \mathrm{a}$.

Crawford AC, Fettiplace R (1985) The mechanical properties of ciliary bundles of turtle cochlear hair cells. J Physiol (Lond) 364:359-379.

Crawford AC, Evans MG, Fettiplace R (1989) Activation and adaptation of transducer currents in turtle hair cells. J Physiol (Lond) 419: 405-434.

Crawford AC, Evans MG, Fettiplace R (1991) The actions of calcium on the mechanoelectrical transducer current of turtle hair cells. J Physiol (Lond) 434:369-398.

Dallos P, Evans BN, Hallworth R (1991) Nature of the motor element in electrokinetic shape changes of cochlear outer hair cells. Nature 350:155-157.

Denk W (1989) Biophysical studies of mechano-electrical transduction in hair cells. PhD thesis, Cornell University.

Denk W, Webb WW, Hudspeth AJ (1989) Mechanical properties of sensory hair bundles are reflected in their Brownian motion measured with a laser differential interferometer. Proc Natl Acad Sci USA 86: 5371-5375.

Eatock RA, Corey DP, Hudspeth AJ (1979) Adaptation in a vertebrate hair cell: stimulus-induced shift of the operating range. Soc Neurosci Abstr 5:19.

Eatock RA, Corey DP, Hudspeth AJ (1987) Adaptation of mechanoelectrical transduction in hair cells of the bullfrog's sacculus. J Neurosci 7:2821-2836.

Gillespie PG, Hudspeth AJ (1992) ADP or an ADP analog blocks adaptation of mechanoelectrical transduction in hair cells. Biophys $\mathbf{J}$ 61:A516.

Hacohen N, Assad JA, Smith WJ, Corey DP (1989) Regulation of tension on hair-cell transduction channels: displacement and calcium dependence. J Neurosci 9:3988-3997.

Holton T, Hudspeth AJ (1986) The transduction channel of hair cells from the bull-frog characterized by noise analysis. J Physiol (Lond) 375:195-227.

Howard J., Hudspeth AJ (1987) Mechanical relaxation of the hair bundle mediates adaptation in mechanoelectrical transduction by the bullfrog's saccular hair cell. Proc Natl Acad Sci USA 84:3064-3068.

Howard J, Hudspeth AJ (1988) Compliance of the hair bundle associated with gating of the mechanoelectrical transduction channels in the bullfrog's saccular hair cell. Neuron 1:189-199.

Huang PL, Corey DP (1990) Calcium influx into hair cell stereocilia: further evidence for transduction channels at the tips. Biophys Soc Abstr 57:530a.

Hudspeth AJ (1982) Extracellular current flow and the site of transduction by vertebrate hair cells. J Neurosci 2:1-10.

Hudspeth AJ (1985) Models for mechanoelectrical transduction by hair cells. In: Contemporary sensory neurobiology (Correia MJ, Perachio AA, eds), pp 193-205. New York: Liss.

Hudspeth AJ (1989) How the ear's works work. Nature 341:397-404.

Hudspeth AJ (1992) Hair bundle mechanics and a model for mechanoelectrical transduction by hair cells. In: Sensory transduction, fortyfifth symposium of the Society of General Physiologists (Corey DP, Roper SD, eds), in press. Rockefeller UP.

Huxley AF (1957) Muscle structure and theories of contraction. Prog Biophys Biophys Chem 7:255-318.

Huxley AF, Simmons RM (1971) Proposed mechanism of force generation in striated muscle. Nature 233:533-538.

Jacobs RA, Hudspeth AJ (1990) Ultrastructural correlates of mechanoelectrical transduction in hair cells of the bullfrog's internal ear. Cold Spring Harbor Symp Quant Biol 55:547-561.

Janmey PA, Hvidt S, Oster GF, Lamb J, Stossel TP, Hartwig JH (1990) Effect of ATP on actin filament stiffness. Nature 347:95-99.

Jaramillo F, Hudspeth AJ (1991) Localization of the hair cell's transduction channels at the hair bundle's top by iontophoretic application of a channel blocker. Neuron 7:409-420.

Jaramillo F, Howard J, Hudspeth AJ (1990) Calcium ions promote rapid mechanically evoked movements of hair bundles. In: The mechanics and biophysics of hearing (Dallos $\mathrm{P}$, Geisler CD, Matthews JW, Ruggero MA, Steele CR, eds), pp 26-33. Berlin: Springer.

Koyama H, Lewis ER, Leverenz EL, Baird RA (1982) Acute seismic sensitivity in the bullfrog ear. Brain Res 250:168-172.

Kroese ABA, Das A, Hudspeth AJ (1989) Blockage of the transduction channels of hair cells in the bullfrog's sacculus by aminoglycoside antibiotics. Hearing Res 37:203-218. 
Mooseker MS, Graves TA, Wharton KA, Falco N, Howe CL (1980) Regulation of the microvillus structure: calcium-dependent solation and cross-linking of actin filaments in the microvilli of intestinal epithelial cells. J Cell Biol 87:809-822.

Ohmori $\mathrm{H}$ (1988) Mechanical stimulation and fura-2 fluorescence in the hair bundle of dissociated hair cells of the chick. J Physiol (Lond) 399:115-137.

Pickles JO, Comis SD, Osborne MP (1984) Cross-links between stereocilia in the guinea pig organ of Corti, and their possible relation to sensory transduction. Hearing Res 15:103-112.

Rusch A, Thurm U (1990) Spontaneous and electrically-induced movements of ampullary kinocilia and stcrcovilli. Hearing Res 48: $247-264$.

Sand O (1975) Effects of different ionic environments on the mechano- sensitivity of lateral line organs in the mudpuppy. J Comp Physiol 102:27-42.

Shepherd GMG, Corey DP, Block SM (1990) Actin cores of hair cell stereocilia support myosin motility. Proc Natl Acad Sci USA 87: 8627-8631.

Shepherd GMG, Assad JA, Parakkel M, Kachar B, Corey DP (1991) Movement of the tip-link attachment is correlated with adaptation in bullfrog saccular hair cells. J Gen Physiol, in press.

Toyoshima YY, Kron SJ, Spudich SJ (1990) The myosin step size: measurement of the unit displacement per ATP hydrolyzed in an in vitro assay. Proc Natl Acad Sci USA 87:7130-7134.

Zenner H, Zimmerman R, Gitter AH (1988) Active movements of the cuticular plate induce sensory hair motion in mammalian outer hair cells. Hearing Res 34:233-240. 